\title{
LA CAPSULE DES LEVURES. MORPHOLOGIE ET CONNAISSANCES BIOCHIMIQUES ACTUELLES
}

\author{
Par Mme H. LENORMAND
}

I. - Historique

La morphologie de la capsule des levures n'a été que peu étudiée jusqu’à présent :

Potron (1903), dans sa thèse de Doctorat en Médecine, expose les recherches faites antérieurement sur cette question par WILL (1895), CaSagrandi (1897) et Vuillemin (1900). Personnellement, il étudie la morphologie capsulaire des Torulopsis et de quelques Saccharomyces, soit dans les tissus de l'hôte infecté, soit en culture. Sa description est déjà très détaillée. Mais, désormais, les auteurs vont se désintéresser de la question, qui va rester en suspens pendant plus de trente ans.

On ne peut, en effet, rapporter à l'étude de la capsule des levures les travaux de LAFAR qui, en 1906, décrit « le réseau gélatineux des levures », en étudie les propriétés chimiques et conclut à la nature glycidique de cette substance. Le mucilage parait être en effet plutôt un produit de sécrétion des levures que l'homologue d'une capsule.

Mais, si l'étude de la capsule des levures est désormais négligée, celle des capsules bactériennes reste à l'ordre du jour chez les bactériologistes. Ceux-ci vont s'attacher surtout à mettre au point des méthodes de coloration applicables dans le domaine de la mycologie et qu'il est intéressant de citer.

Legroux et Magrou (1920) découvrent une méthode de coloration des capsules bactériennes dans les tissus. Cette méthode, un peu modifiée, permettra à Legroux, en 1925 , de rechercher les rapports de la capsule avec la virulence des germes. Pour cet auteur, la capsule serait un gonflement de l'ectoplasme bactérien (l'ectoplasme étant l'homologue de la membrane) et jouerait un rôle dans les phénomènes de virulence.

Gutstern (1924) publie plusieurs mémoires sur une méthode Ann, de Parasitologie, t. XXIII, Nos 1-2. - 1948, p. 55-106. 
générale pour la mise en évidence de l'ectoplasme des bactéries Gram positives. Dans son troisième mémoire, il étend d'ailleurs cette méthode aux levures. Mais ses procédés de coloration ne s'avèrent pas toujours fidèles et de nombreux autres auteurs vont s'attacher à en trouver de meilleurs. Nous citerons seulement parmi eux :

Borin (1925) qui emploie l'encre de Chine avec une émulsion de la culture dans du sérum animal frais.

Churchman et Emelianoff (1933) qui utilisent le colorant de Wright et une solution de Clark et Lubbs tamponnée à $p \mathrm{H} 6,4$.

Howie et KirkPatrick (1934) qui proposent une coloration combinée à l'éosine et à la fuchsine.

Butt, Bonynge et Joyce (1936) qui se servent d'encre de Chine diluée dans du glycose à 6 pour 100 .

Jean Brenot (1939) qui, dans sa thèse de Doctorat vétérinaire, passe en revue les principales colorations employées en bactériologie pour mettre en évidence les capsules des germes, soit dans les tissus, soit en culture.

Dosch (1942) qui colore avec une solution à 2,5 p. 100 de prontosil.

Nous n'avons cité que les principaux auteurs ayant donné des techniques de coloration qui nous ont paru intéressantes, mais beaucoup d'autres ont abordé le même sujet avec plus ou moins de succès.

Cette question des bactéries capsulées a posé de nombreux problèmes chimiques, biologiques, immunologiques, à l'étude desquels se sont attachés de nombreux auteurs. Tout récemment, R. Dubos (1946), dans The Bacterial Cell, en a fait une étude complète.

Les mêmes problèmes se posaient pour les levures, mais l'absence à peu près complète de pouvoir pathogène chez la plupart d'entre elles devait longtemps gêner les recherches immunologiques.

La seule levure vraiment très pathogène pour l'homme est Torulopsis neoformans. Celle-ci donne en effet une méningo-encéphalite toujours mortelle et dont le diagnostic peut se faire par l'étude du liquide céphalo-rachidien. A l'autopsie, on retrouve le champignon

\section{Planche III}

FIG. 1. - Endomycopsis vernalis. - Culture de 5 jours. Longs filaments avec capsule bien développée. Souche $\mathrm{n}^{\circ} 130$.

Fic. 2. - Saccharomyces fragilis. - Culture de 30 jours. Blastospores et filaments formant pseudomycelium. Cellules et filaments sont entourés de leur capsule, commune aux points de contact. Souche $\mathrm{n}^{\circ} 1.049$.

Fic. 3. - Ashbya gossypii. - Culture de 5 jours. Filaments à capsule très nette. Bourgeonnement intra-capsulaire. 

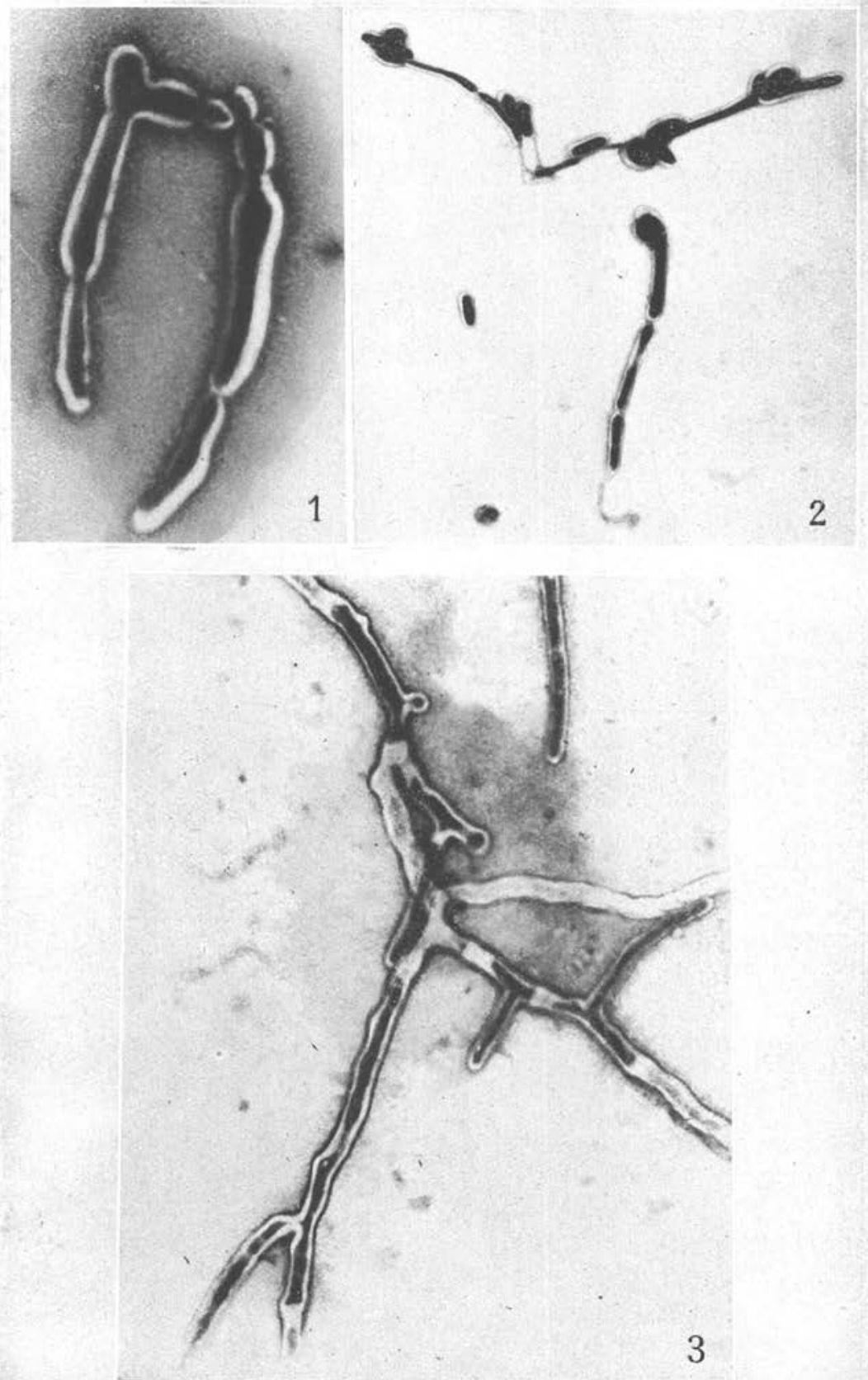

Masson et Cie, Editeurs 

dans différents viscères et notamment dans le cerveau. Cette levure est très intéressante par sa morphologie même qui la distingue des autres levures. Elle possède une capsule volumineuse et tout particulièrement développée chez l'hôte infecté. Aussi est-ce avec Torulopsis neoformans que l'étude de la capsule des levures va être reprise, par Flavio L. Niño (1934) qui, à propos d'un travail essentiellement clinique et anatomo-pathologique, fait une étude assez sommaire de la capsule.

Cependant, faisant exception, Negroni décrit en 1935 la morphologie de la capsule de Mycotorula (Candida) albicans et, non rebuté par le faible pouvoir pathogène de cette levure, étudie, en 1936, les propriétés allergiques et antigéniques de sa substance capsulaire.

Désormais, les travaux les plus récents vont concerner Torulopsis neoformans et, notamment en 1938, DE Busscher, Scherer et Thomas donnent une description de la capsule qui rappelle de très près les travaux de Potron, bien que ces auteurs ne semblent pas en avoir eu connaissance et ne le citent pas dans leur bibliographie.

Tout récemment, J. Mager et M. Aschner (1947) ont étudié les conditions de production d'amidon extra-cellulaire par les levures encapsulées, en particulier par de nombreuses espèces de Torulopsis dont Torulopsis rotundata et Torulopsis neoformans.

Ainsi, la capsule des levures n'a été jusqu'ici l'objet que d'études peu nombreuses et fragmentaires. Cependant, les résultats obtenus encourageaient à des recherches plus poussées et plus étendues.

Pour étudier la morphologie de la capsule des levures, il fallait posséder une méthode sûre, permettant d'obtenir des résultats concordants et éliminant les effets des variations individuelles de manipulation ou des réactions différentes de la part des diverses souches.

C'est pourquoi, à la recherche du meilleur procédé, nous avons essayé différentes techniques, dont nous allons maintenant donner la description.

\section{II. - MÉthodes de coloration des Capsules}

Les principales méthodes de coloration des capsules vont être rappelées brièvement. La plupart de ces méthodes ont été transposées, au cours de ce travail, des bactéries aux levures. Certaines d'entre elles n'ont pu être exécutées par suite de l'impossibilité d'obtenir les produits nécessaires.

Le but de toutes ces techniques est de colorer électivement la 
capsule, avec un colorant dont la teinte contraste avec celle du colorant somatique. Il est en effet possible, par des procédés très simples, comme l'émulsion de la culture dans le lugol ou dans une goutte d'encre de Chine, de voir la capsule. Mais celle-ci se présente sous forme d'un halo incolore, entourant le corps bactérien ou la levure, et contrastant avec le fond plus coloré de la préparation. C'est pour confirmer la réalité de ces capsules vues en " négạtif 》 que de nombreuses techniques de coloration capsulaire ont été proposées.

\section{Méthode de Hunton (1932)}

Le protocole de cette méthode est reproduit d'après NEgRonI (1935).

Emulsionner et étaler sur lame la culture dans le mélange suivant :

Sol. de nutrose (caséinate de sodium) à 3 p. 100

(stérilisée à la vapeur fluente) ............. $100 \mathrm{~cm}^{3}$

Sol. d'acide phénique à 2 p. $100 \ldots \ldots \ldots \ldots \ldots . \quad 5 \mathrm{~cm}^{3}$

L'étalement, séché et non fixé, est coloré pendant trente secondes par le colorant de Hunton, dont voici la formule :

Acide phénique à 2 p. 100 (sol. aq.) ........... $100 \mathrm{~cm}^{3}$

Acide lactique pur $\ldots \ldots \ldots \ldots \ldots \ldots, 0 \mathrm{~cm}^{3} 25$ à $\quad 0 \mathrm{~cm}^{3} 50$

Acide acétique à 1 p. $100 \ldots \ldots \ldots \ldots \ldots \ldots \ldots . \quad 1 \mathrm{~cm}^{3}$

Solution alcoolique saturée de fuchsine basique... $1 \mathrm{~cm}^{3}$

Fuchsine phéniquée vieillie ............... $1 \mathrm{~cm}^{3}$

Laver, sécher, examiner : les cellules de levure sont colorées en rouge, la capsule est colorée en rose. D'après Ntgroni, un espace clair sépare la capsule du corps cellulaire ; souvent, la capsule se gonfle et présente un aspect stratifié.

\section{Méthode de Kufferath (1929)}

C'est une méthode pour la coloration des ascospores, adaptée aux capsules. Elle a été modifiée par LANGeron et Guerra (1938).

Emulsionner la culture dans de l'eau distillée, sur une lame parfaitement dégraissée, et étaler. Il est préférable de ne pas faire bouillir l'émulsion pendant l'étalement comme le préconise Guerra. Lorsque l'étalement est sec, fixer par la chaleur, puis recouvrir la 
lame avec la solution de fuchsine basique phéniquée de Ziehl. Chauffer jusqu'à l'ébullition. Laisser refroidir, puis laver rapidement à l'eau. Différencier en quelques secondes par l'alcool lactique à 2 p. 100. Laver et colorer pendant trente secondes avec une solution à 1 p. 100 de chlorhydrate de bleu de Nil. Laver et, avant que la lame ne soit sèche, étaler une goutte d'encre de Chine.

La capsule non déformée est en négatif sur le fond noir. Les cellules sont en bleu, les ascospores en rouge. Cette coloration donne de bons résultats en cultures sur lame.

\section{Procédé de BoRin à l'encre de Chine (1925)}

Sur des lames parfaitement dégraissées (bichromate de potassium et acide sulfurique), on étale en couche très mince un sérum quelconque et on dessèche à chaud. Après refroidissement, on mélange, avec une goutte d'encre de Chine, une goutte d'émulsion de culture, on étale et on inonde de xylol le frottis encore humide. On laisse égoutter et on fait tomber, d'une hauteur de un centimètre, une goutte d'huile de cèdre. On examine sans lamelle les seuls germes fixés à la lame par le sérum.

\section{Procédé de Butt, Bonynge et Joyce (1936)}

C'est encore un procédé à l'encre de Chine.

Ces auteurs obtiendraient de meilleurs résultats en diluant l'encre de Chine avec du glycose à 6 p. 100, au lieu d'eau distillée, et avec de l'azobleu.

\section{Méthode de Dosch (1942)}

Dosch colore les capsules des bactéries en employant la solution rouge de prontosil soluble du commerce, ou rubiazol.

Le frottis, non fixé, est coloré pendant deux minutes avec une solution à 2,5 p. 100 de prontosil et, sans laver, on sèche au buvard.

Les microorganismes seraient colorés en rouge et entourés d'une étroite zone incolore incluse dans une large zone rouge. C'est cette dernière qui, pour l'auteur, représenterait la capsule.

\section{Procédés de Gutstein}

Dans une série de cinq Mémoires, Gutstern fait une étude complète des capsules et donne une méthode générale de coloration. 
Dans son premier Mémoire, il étudie une « Méthode générale pour la mise en évidence de l'ectoplasme des bactéries Gram positives ». Il retranscrit deux méthodes de EISENBERG.

Dans une première méthode, il colore par le violet de méthyle, puis traite la préparation par une solution aqueuse concentrée d'acide picrique et différencie par le chloroforme.

Dans une deuxième méthode, il colore avec une solution d'aurantia dans l'alcool méthylique et fait ensuite agir le violet de méthyle.

Il obtient les résultats suivants : l'ectoplasme est violet, l'endoplasme reste en négatif.

Ensuite, Gutstein expose le principe de sa méthode. L'ectoplasme de toutes les bactéries Gram positives se colore avec presque tous les colorants basiques en solution aqueuse. De plus, cette méthode permet de mettre en évidence, par une double coloration contrastée, le corps bactérien et la capsule. Enfin, l'ectoplasme chromophobe doit être soumis à un mordançage énergique au tanin pour être coloré.

Pour Gutstern, le mordançage a pour but de modifier la gaine bactérienne et d'empêcher la pénétration du colorant dans le corps cellulaire. Voici l'exemple qu'il donne à l'appui de sa théorie : si on arrose du papier-filtre en quatre ou six épaisseurs avec une solution à 1 p. 100 de vert malachite, toutes les couches sont colorées en vert foncé. $\mathrm{Si}$ on arrose la première couche avec une solution étendue de tanin, puis l'ensemble avec le vert malachite, le colorant ne pénètre pas plus loin que la deuxième ou troisième couche. Les couches superficielles sont alors vert-de-gris et non vert foncé.

Les meilleurs colorants basiques sont :

Bleu de méthylène.

Azur II.

Thionine.

Vert malachite.

Vert brillant.

Vert d'iode.

Safranine.
Pyronine.

Rouge neutre.

Fuchsine basique.

Violet de gentiane.

Violet de méthyle $\mathrm{N}$ bleu (Agfa) (1).

Bleu Victoria.

Bleu de toluidine.

Il étend sa méthode aux levures et note les résultats suivants :

$1^{\circ} \mathrm{Si}$ on colore par la méthode au tanin, la membrane des levures est colorée, alors que le corps (endoplasme) est faiblement coloré.

(1) Qui est un mélange de tétra, penta et hexa méthylpararosanilines. 
Mais si, après avoir coloré en premier lieu l'endoplasme avec un colorant basique foncé (bleu de méthylène), on mordance par le tanin, puis on colore avec un colorant basique clair (safranine), on obtient une belle double coloration : l'endoplasme est bleu, l'ectoplasme est rouge.

$2^{\circ}$ En utilisant un colorant basique clair (phosphine), puis en mordançant au tanin et enfin en colorant avec un colorant basique foncé (violet de méthyle), on obtient les résultats suivants : la bordure est violet foncé, le centre (endoplasme) est jaune clair avec reflet violet.

\section{Voici la méthode au tanin décrite par Gutstein :}

Emulsionner dans une goutte d'eau distillée une très petite quantité d'une culture sur milieu solide, puis étaler avec l'anse de platine.

Fixer par la chaleur, ou par une solution aqueuse saturée de sulfate de magnésium ou d'ammonium.

Mordancer pendant deux minutes par du tanin à 5 p. 100, puis laver à fond à l'eau.

Colorer à froid, en trente secondes ou une minute, par un colorant basique en solution aqueuse à 1 p. 100 .

$\mathrm{Si}$ on veut mettre en évidence l'endoplasme, il faut faire agir le colorant approprié avant le mordançage ; puis colorer avec un colorant basique de contraste à froid, afin de limiter la pénétration du colorant à l'ectoplasme.

Gutstein donne pour les levures les exemples suivants :

a. Tanin-safranine : ectoplasme rose, ainsi que la paroi des ascospores.

b. Vert brillant phéniqué-tanin-safranine : faire agir le vert pendant trois minutes, mordancer et colorer en trente secondes par la safranine : les ascospores sont vert clair, l'endoplasme vert bleuâtre, la paroi des ascospores et l'ectoplasme rouges.

Pour colorer différemment les ascospores et l'endoplasme, il faut faire agir d'abord un colorant phéniqué à chaud, puis différencier par l'acide acétique jusqu'à décoloration complète, et faire agir ensuite un colorant basique de contraste à froid.

c. Violet phéniqué-acide acétique-vert brillant-tanin-safranine: faire agir le violet pendant une minute à chaud, différencier par l'acide acétique à 5 p. 100 , colorer en trois minutes à froid par le vert brillant, mordancer et enfin colorer en trente secondes par la safranine : les ascospores sont violettes, l'endoplasme vert bleuâtre, eapsule et ectoplasme rouges.

d. Bleu phéniqué-phosphine-tanin-safranine : les ascospores sont bleues, l'endoplasme jaune, capsule et ectoplasme rouges. 
Dans ses troisième et quatrième Mémoires, Gutstein poușse plus loin l'analyse de l'ectoplasme des levures et montre qu'il est formé de deux couches, une interne épaisse, bien délimitée, une externe délicate, sans limites précises et formant un anneau flou. Ces détails peuvent être mis en évidence par les méthodes suivantes:

e. Tanin-vert de Guinée: mordancer par le tanin à 30 p. 100, laver à fond et colorer deux minutes par le vert de Guinée à 1 p. 100. La partie interne de l'ectoplasme est vert foncé, le reste est vert clair.

f. Phosphine phéniquée-vert de Guinée: coiorer cinq minutes par la phosphine phéniquée, laver, colorer trente secondes par le vert de Guinée. L'endoplasme est jaune, l'ectoplasme vert.

g. Ferrocyanure-bleu Victoria-tanin-safranine: cette méthode permet de colorer les deux couches de l'ectoplasme en deux couleurs contrastantes. Traiter pendant cinq minutes, par le ferrocyanure de potassium de 2 à 10 p. 100, le frottis fixé par la chaleur. Laver à fond, colorer trois minutes par le bleu Victoria à 1 p. 100, laver, mordancer, laver et colorer quinze secondes par la safranine.

\section{Technique de Churchman et Emelianoff (1933)}

Cette technique sera reprise dans un chapitre ultérieur ; c'est elle qui a servi de base à nos recherches.

\section{Technique de Howie et Kirkpatrick (1934)}

Ces auteurs préparent la solution suivante :

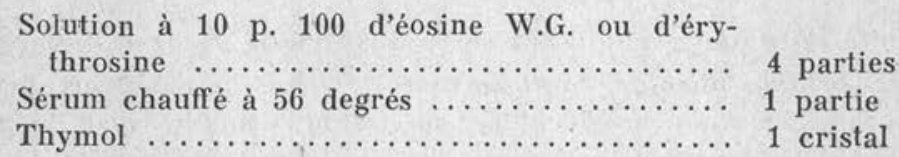

Laisser reposer plusieurs jours, centrifuger, garder le liquide limpide. Prélever une anse de ce liquide, une anse de Ziehl dilué au cinquième. Colorer une demi-minute avec ce mélange l'émulsion bactérienne. Ajouter une anse d'éosine, attendre une minute, étaler, sécher.

Les bactéries sont colorées par la fuchsine, les capsules se détachent incolores sur le fond rouge d'éosine.

\section{Techniques de Potron (1903)}

Cet auteur emploie deux méthodes très simples.

La première est empruntée à STRASSBuRger : émulsionner la cul- 
ture dans le bleu de toluidine concentré, étaler, sécher et décolorer rapidement à l'alcool. La cuticule se colore en rouge, le corps de la levure en bleu.

La deuxième technique lui est personnelle : il dépose sur la lame une petite goutte d'une émulsion de la culture sur milieu solide. Il recouvre d'une lamelle et fait arriver par un des côtés une goutte de bleu de toluidine concentré.

Résultat: la coloration est d'autant plus intense que l'élément est plus âgé. La coloration diminue d'intensité en allant vers le centre de la lamelle. Seule la « cuticule » est colorée et permet de décrire certains détails que nous exposerons plus loin.

Certains auteurs se sont attachés à mettre en évidence la capsule des bactéries ou des levures au sein même des tissus.

\section{Méthodes de Legroux et Magrou}

En 1920, R. LEgroux et J. Magrou font connaître l'état organisé des colonies bactériennes en étudiant des coupes de ces colonies fixées à l'alcool-formol et colorées par un mélange d'éosinates de bleu de méthylène et de bleu de toluidine.

Voici leur technique : imbiber de formol le coton du tube de culture pendant 24 heures, afin de tuer la colonie, puis la fixer dans un mélange à parties égales de formol et d'alcool à 80 degrés. Faire des coupes au $1 / 300,1 / 500,1 / 1.000$. Après déparaffinage, laver à l'alcool méthylique, puis colorer par :

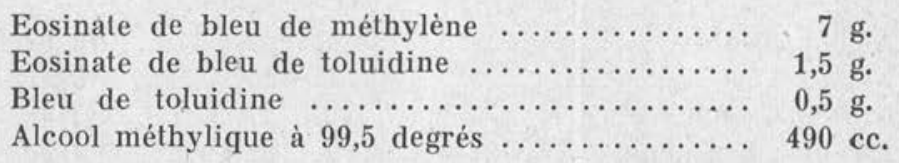

Opérer dans une boîte de Laveran. Couvrir la lame avec $1 \mathrm{~cm}^{3} \mathrm{de}$ colorant; au bout d'une minute, ajouter $4 \mathrm{~cm}^{3}$ d'eau distillée neutralisée ; puis retourner la lame et laisser colorer, face en dessous, pendant dix à quinze minutes. Laver à l'eau ordinaire et différencier par le tanin orange R.A.L. au quart, dans l'eau distillée neutralisée. La gélose doit prendre une teinte bleue. Déshydrater à l'alcool à 95 degrés. Toluène. Huile de cèdre.

L'endoplasme est violet, l'ectoplasme bleu azur.

Legroux, en 1925, publie de nouveaux détails pour la mise en évidence de l'ectoplasme qu'il identifie à la capsule. 
Voici sa technique : émulsionner une parcelle de culture jeune de seize heures à dix-huit heures dans une goutte constituée par :

Sérum de mammifères $\ldots \ldots \ldots \ldots \ldots \ldots \ldots .1$ partie

Eau ordinaire $\ldots \ldots \ldots \ldots \ldots \ldots \ldots \ldots \ldots, 2$ parties

Etaler le mélange et, avant dessiccation, fixer par les vapeurs d'acide osmique (solution aqueuse à $0,5 \mathrm{p}$. 100) pendant vingt à trente secondes. Laisser sécher et verser quelques gouttes d'alcool. Colorer par le bleu de méthylène ou le bleu de toluidine, tous deux colorants métachromatiques, ou bien encore par les éosinates de bleus de méthylène et de toluidine.

Le résultat obtenu est le suivant : l'ectoplasme est bleu pâle, l'endoplasme est violet pour les germes vivants, rouge pour les germes morts.

\section{Méthode de NissL}

Cette méthode a permis à certains auteurs (DE Busscher, ScheRER et THomas) de bien mettre en évidence l'architecture si particulière de la capsule de Torulopsis neoformans. Les images décrites par ces auteurs sont identiques à celles déjà publiées par Potron en 1903 et obtenues par une méthode de coloration différente.

La méthode originale de Nissl n'est plus employée actuellement. On a recours au procédé de de Gothard:

Fixer les préparations à l'alcool à 96 degrés et inclure au collodion ou à la paraffine. Colorer pendant 24 heures à froid dans le bleu polychrome de Unna. Laver rapidement à l'alcool à 80 degrés. Différencier par le mélange de de Gothard:

Alcool ábsolu $\ldots \ldots \ldots \ldots \ldots \ldots \ldots \ldots \ldots \ldots, 16 \mathrm{cc}$.

Xylol $\ldots \ldots \ldots \ldots \ldots \ldots \ldots \ldots \ldots \ldots \ldots \ldots \ldots \ldots \ldots, 5$ cc.

Créosote de hêtre $\ldots \ldots \ldots \ldots \ldots \ldots \ldots \ldots \ldots \ldots, 5$ cc.

Essence de cajeput $\ldots \ldots \ldots \ldots \ldots \ldots \ldots \ldots \ldots .4 \mathrm{cc}$.

\section{Planche IV}

Fig. 1. - Candida krusei. - Culture de 30 jours. Microphotographie d'une plage cellulaire bien encapsulée. Souche 1.046.

Fif. 2. - Mycoderma vini. - Culture de 3 jours. Cellules à ectoplasme linéaire ; capsules très développées, le soma cellulaire est souvent excentré. Souche $\mathrm{n}^{\circ} 126$.

kıG. 3. - Debaryomyces klöckeri. - Culture de 24 heures. Aspect général de la capsule. Les cellules les plus jeunes sont les plus fortement colorées.

Fig. 4. - Saccharomyces muciparis. - Culture de 24 heures. Plage cellulaire dont la bordure capsulaire est très nette. Aspect en mosaïque avec amas de colorant aux angles dièdres. 
ANNALES DE PARASITOLOGIE

T. XXIII, Nos 1-2, 1948.
Planche IV

(Mémoire Lenormand)
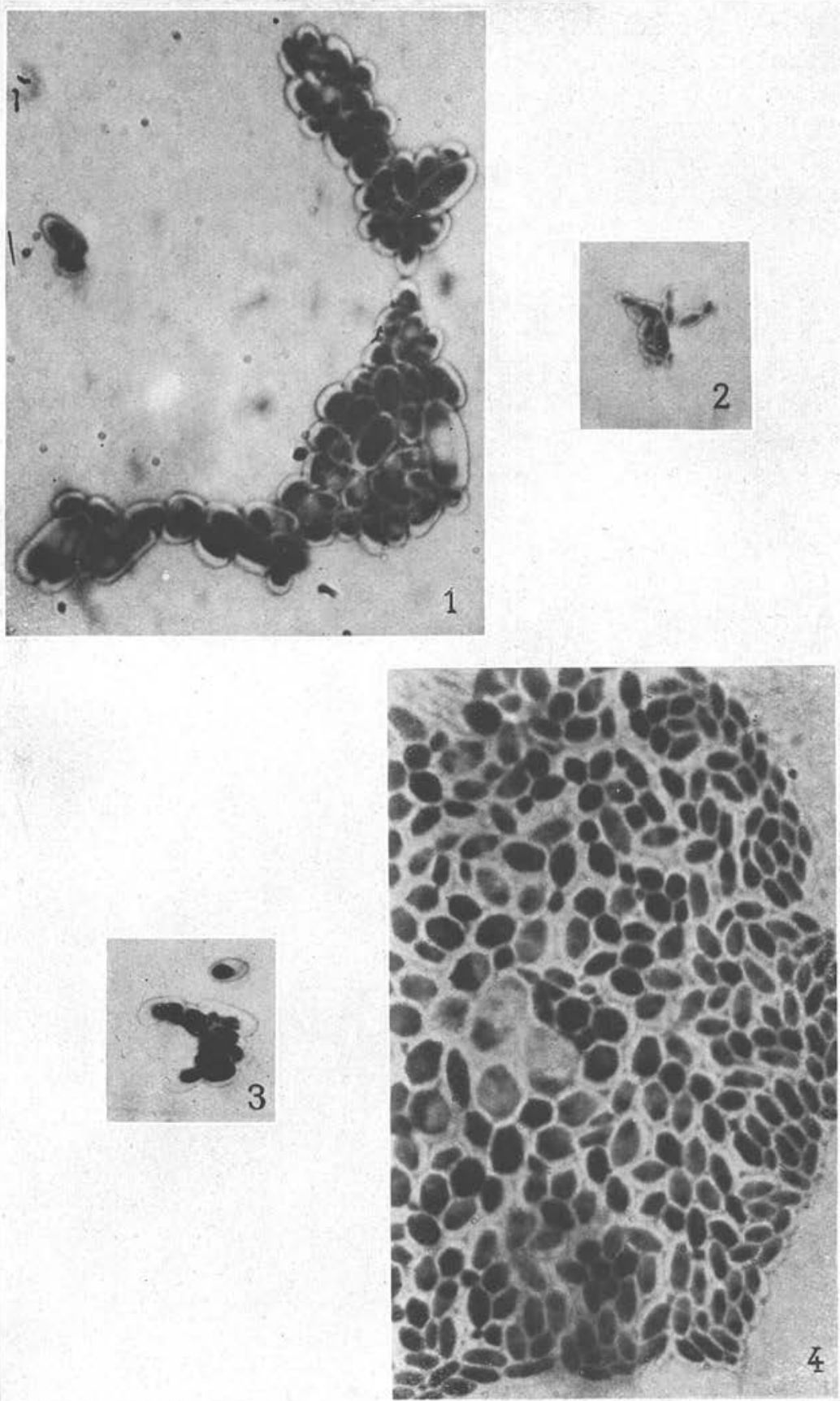

Masson et Cie, Editeuns 
Laver à l'alcool absolu, puis au xylol et monter à l'huile de cèdre.

On obtient d'aussi bons résultats en employant comme colorant :

le bleu de méthylène à 1 p. 500 ,

le bleu de toluidine à 1 p. 100 ,

la thionine à 1 p. 100 ,

et comme différenciateur :

l'eau acétifiée à 1 p. 500 .

De Busscher, Scherer et Thomas ont employé comme colorant la thionine.

12. Brenot, en 1938, dans sa Thèse de Doctorat vétérinaire, indique quelques méthodes de coloration des capsules bactériennes dans les tissus. Voici ces différentes méthodes :

Méthode de Pirbert.

Colorer les lamelles ou les coupes pendant quelques minutes dans le mélange suivant saturé de violet de dahlia:

Eau distillée $\ldots \ldots \ldots \ldots \ldots \ldots \ldots \ldots \ldots \ldots, 100$

Alcool ............................ $\quad 50$

Acide acétique $\ldots \ldots \ldots \ldots \ldots \ldots \ldots \ldots \ldots \ldots \ldots, \quad 2,5$

La durée d'immersion doit être très courte, la coloration se faisant presque instantanément. Laver à l'eau, sécher et monter au baume.

Les germes sont en bleu foncé, les capsules en bleu clair.

Dans la Méthode de Conkey, le colorant est plus complexe. Voici la formule de la solution conseillée :

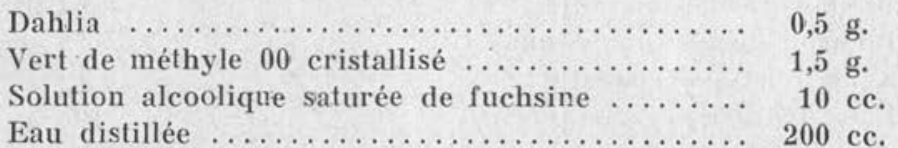

Friedlander, pour la coloration des capsules du pneumocoque, indique la technique suivante :

Il colore les coupes pendant 24 heures dans un bain constitué par :

Solution concentrée de violet de gentiane ..... $50 \mathrm{~g}$.

Eau distillée $\ldots \ldots \ldots \ldots \ldots \ldots \ldots \ldots \ldots \ldots, 100 \mathrm{~g}$.

Acide acétique $\ldots \ldots \ldots \ldots \ldots \ldots \ldots \ldots \ldots \ldots, \quad 19 \mathrm{~g}$.

Après lavage à l'eau, additionnée de 1 p. 100 d'acide acétique, il déshydrate par l'alcool et éclaircit les préparations à l'essence de cèdre. Monter au baume.

Les capsules restent souvent colorées, mais elles tranchent par leur teinte claire sur le corps cellulaire plus foncé.

Ann, de Parasitologie, t. XXIII, Noy $1-2,-1948$. 


\section{Méthode de Malone.}

Cette méthode fait intervenir deux colorations contrastées :

La première est une coloration dans une solution à 1 p. 100 de rouge Congo pendant une minute. Laver, sécher à l'air et traiter par une solution d'acide chlorhydrique à 1 p. 100 dans l'alcool à 96 degrés.

Pour la deuxième coloration, plonger la préparation pendant une minute dans tine solution de violet de méthyle à 5 p. 100. Laver et sécher.

Le fond est bleuâtre, les bactéries et leurs capsules sont violettes.

\section{Méthode de von RicinsDiJK.}

Prendre un tube à hémolyse; $y$ laisser tomber cinq gouttes d'une solution de protargol à 1 p. 100. Dans ce liquide dissocier une parcelle de la culture à examiner. Ajouter ensuite cinq gouttes de la solution d'éosine alcalinisée avec du carbonate de sodium (une goutte de la solution à 20 p. 100 de carbonate de sodium pour un centimètre cube de la solution d'éosine à 2 p. 100). Laisser reposer dix à vingt minutes. Prélever alors une anse, l'étaler, sécher et examiner à l'immersion.

Le fond de la préparation est rouge, le corps bactérien rosé, et la capsule incolore est bordée à sa périphérie d'un cercle rouge très marqué.

\section{Méthode de Carpano.}

Cette méthode a été décrite par CaRpano pour mettre en évidence certains germes pathogènes pour les animaux, tels que Streptococcus equi, Bacterium equisepticum, B. suisepticum, B. mallei et B. typhi. Pour les trois premiers, il fixe par les vapeurs d'acide osmique et colore par la fuchsine ou le cristal violet phéniqués. Le bacille morveux est fixé par la solution suivante, très voisine de celle de Zenker :

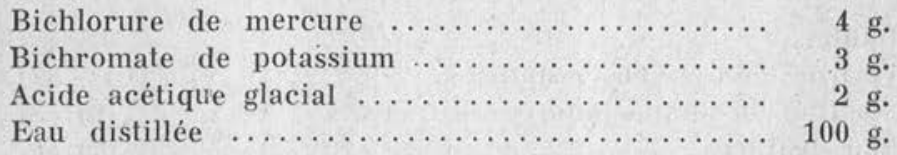

Il est ensuite coloré par la fúchsine phéniquée. Le bacille typhique, après dessiccation à l'air, est traité par les deux solutions suivantes :

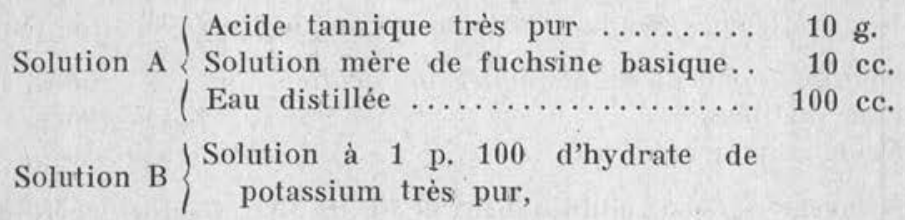

Couvrir le frottis avec cinq ou six gouttes de la solution A; laisser tomber au centre de la préparation deux ou trois gouttes de la solution B ; chauffer légèrement jusqu'à production de vapeurs et d'un léger voile irrisé à la surface. Au bout de quatre à cinq minutes, laver, sécher et monter au baume. 
Il est nécessaire que les lames soient très propres. Sur les préparations bien réussies les capsules sont, soit en négatif, soit en positif. On voit même les cils ou flagelles du bacille typhique, au nombre d'une douzaine, issus non du corps microbien mais de la capsule.

En résumé, ces diverses méthodes peuvent être réunies en deux groupes :

Dans un premier groupe, toutes les méthodes qui ne colorent pas la capsule proprement dite, mais qui la mettent en évidence d'une manière indirecte, par l'existence d'un fond coloré sur lequel se détache la capsule en « négatif ».

Dans un deuxième groupe, c'est la coloration de la capsule qui tient la première place. C'est là que nous avons retenu les méthodes les plus intéressantes, car ce sont elles seules qui ont mis en évidence la morphologie intime de la capsule.

\section{III. - Etude CRitique des MÉthodes de Coloration}

Les nombreuses méthodes qui viennent d'être énumérées sont de valeur très inégale. Dans leur étude critique, nous nous arrêterons d'abord aux colorations des levures en culture, puis nous passerons en revue les colorations dans les tissus,

\section{A. - En culture}

1. - Méthodes qui ne colorent pas la capsule mais la laissent apparaitre en négatif sur le fond coloré

Au premier chef, la plus ancienne, connue de tous les auteurs, est la méthode à l'encre de Chine ou méthode de Burri. On l'emploie couramment en bactériologie et en mycologie. Elle montre toujours autour de la cellule un halo incolore qui ne se laisse jamais pénétrer par l'encre de Chine. Cependant, A. Filıipe nie toute signification à ce halo, qui selon lui ne correspond pas à la capsule, mais serait le « résultat d'un phénomène physico-chimique », car on le retrouverait encore chez les bactéries non capsulées ; de même, ses dimensions seraient modifiées par les différentes températures de séchage et les différents liquides employés pour l'émulsion. Il y aurait donc une question de tension superficielle qui entrerait en jeu.

Cette méthode servant de base, certains auteurs se sont attachés à la perfectionner en la compliquant. Malgré l'extrême complexité de la méthode de Borin (1925) que nous avons déjà décrite, les 
résultats sont décevants, la capsule apparaît toujours en négatif et les images sont beaucoup moins belles et moins constantes qu'avec la méthode de Burri.

Butt, Bonynge et Joyce (1936) se contentent de mélanger l'encre de Chine avec une solution de glycose à 6 p. 100 . Les résultats sont nettement moins bons que par la méthode de Burri. Le mélange de l'azobleu avec l'encre de Chine nous a été impossible à réaliser : les matériaux que nous possédions précipitant lorsqu'on les mettait en contact.

L'emploi du Lugol double est très répandu en zymologie. Si l'examen a lieu entre lame et lamelle avec un objectif à sec, on obtient une belle aréole réfringente, véritable « zone de répulsion » pour les autres globules de levure. Pour la plupart des levures, la capsule se réduit à cet aspect et ne révèle aucunement son architecture interne. Cependant, chez Torulopsis neoformans (voir pl. VII, fig. 1, souche 632), la capsule est parfaitement nette avec un aspect réticulé. En effet, lorsqu'on laisse sécher la préparation et qu'on examine ensuite avec l'objectif à immersion, on obtient l'image suivante : le soma brun foncé est séparé par un espace libre d'une large aréole granuleuse jaune clair, contrastant nettement sur le fond. Ceci ne se voit que sur une culture jeune de 24 à 48 heures. Cette coloration est donc intéressante puisqu'elle est simple et rapide. C'est par elle que J. Mager et M. Aschner ont mis en évidence l'existence de grains d'amidon intracapsulaires.

Cependant, à l'exception du cas de Torulopsis neoformans, ces méthodes sont imparfaites, la capsule apparait comme une atmosphère enveloppant le corps cellulaire ; mais aucune architecture interne et même aucune limite externe n'ont pu être ainsi précisées.

\section{2. - Méthodes recherchant une coloration élective de la capsule}

Elles sont innombrables, et leur grand nombre est le témoignage de leur imperfection.

Les méthodes de Gutstern, malgré les principes bien définis qui ont présidé à leur établissement, donnent de mauvais résultats. Le mordançage par le tanin a pour effet de sensibiliser la cellule au colorant qui se fixe intensément, et sans distinction, sur le corps bactérien et la capsule. On obtient de plus belles images capsulaires en faisant agir les deux colorants sans interposition du mordant. Les résultats sont bien supérieurs encore si, après fixation, on fait agir une solution à 5 p. 190 de tanin pendant cinq minutes. 
On lave minutieusement et on fait agir les deux colorants (vert brillant, safranine, par exemple), en ayant soin de laver entre les deux colorations. On obtient la coloration suivante, assez bien contrastée lorsqu'elle est réussie : la capsule est colorée en vert, tandis que le corps cellulaire est rouge.

Nous avons modifié la technique de Gutstein comme suit :

a) Fixation par l'alcool.

b) Coloration en trente secondes par le vert brillant.

c) Lavage à l'eau, d'abord, puis à l'eau acétifiée à 1 p. 500 .

d) Faire alors agir une solution à 5 p. 100 de tanin pour mordancer.

e) Laver et colorer quinze secondes par la safranine.

Par cette technique, nous avons obtenu de bons résultats : le corps de la levure est vert, la capsule est rouge vif. L'emploi du bleu Victoria, au lieu de vert brillant, nous a donné de bonnes images capsulaires. Dans ce cas, chaque cellule est entourée d'une large aréole réticulée rouge, séparée du soma cellulaire bleu par une zone circulaire claire. Dans certaines préparations, la capsule était traversée de part en part par des filaments issus de granulations rouges situées en bordure. Cependant, malgré les quelques bons résultats obtenus, la méthode de Gutstein ne mérite pas d'être retenue, car elle est très infidèle, donnant de très belles images capsulaires chez certaines levures à capsule très développée, comme les Torulopsis, mais incapable de faire apparaitre les capsules moins exubérantes des Candida et des Debaryomyces.

La méthode de J. W. Howie et J. Kirkpatrick (1934) utilisant un mélange éosine-fuchsine et celle de Dosch (1942) au Prontosil ne doivent être citées que pour mémoire, tant les résultats en sont inconstants. Dans les meilleures préparations, la limite externe de la capsule est seule indiquée. Avec le Prontosil, aucun contraste n'existe entre capsule et corps cellulaire. L'image obtenue est empâtée, la capsule étant un peu plus claire que le soma.

Negroni (1935) a obtenu de belles images chez Candida albicans avec la coloration de Hunton. Une photographie publiée dans son article montre des capsules parfaitement colorées et présentant des stratifications remarquables. Malheureusement, par manque de nutrose, nous n'avons pu reproduire exactement cette technique, et la coloration par le colorant de Hunton seul est peu satisfaisante.

De la longue liste de techniques reproduite par J. Brenot, nous retiendrons deux faits :

a) Les différentes méthodes qui s'adressent à la coloration des 
capsules de levures au sein des tissus animaux donnent toujours de bons résultats, car la capsule est alors particulièrement développée et se laisse bien colorer.

b) Les méthodes destinées à la coloration des capsules de levures cultivées in vitro sont compliquées, difficiles à réaliser et font appel (méthode de Carpano) à des substances telles que acide acétique glacial, bichlorure de mercure, hydrate de potasse, dont l'action puissante et brutale peut perturber la véritable architecture cellulaire. Quant aux méthodes employant le violet de gentiane, elles n'ont absolument aucun cours en mycologie ; ce corps ne permet en aucun cas l'obtention de colorations fines et bien différenciées du protoplasme cellulaire et de ses annexes.

La méthode de Potron (1903), au contraire, nous a paru intéressante. Elle est simple et ne fait appel à aucune manœuvre traumatisante pour les cellules. Nous l'avons décrite dans un chapitre précédent. Cependant, elle ne donne de très bons résultats que pour le genre Torulopsis et en particulier pour $T$. neoformans. C'est grâce à cette méthode au bleu de toluidine que Potron a décrit l'aspect en bogue de châtaigne de la capsule de Torulopsis neoformans.

Nous rapprocherons de cette méthode, par analogie des résultats, celle de Nissl, modifiée par de Gothard. Les auteurs qui l'employèrent (DE Busscher, Scherer et Thomas, 1938) colorèrent par la thionine à 1 p. 100. Il nous a été impossible d'obtenir de bonnes images avec ce colorant. Au contraire, un séjour prolongé, de trois à quatre jours, dans une solution déjà vieille de bleu de toluidine à 1 p. 100 , nous a permis d'obtenir, avec Torulopsis neoformans, à peu près les mêmes figures que celles décrites par ces auteurs.

\section{B. - Dans les tissus}

Cette revue critique ne saurait être complète si nous n'abordions maintenant les techniques de coloration des capsules des levures au sein des tissus humains ou animaux.

\section{Planche V}

Fig. 1. - Saccharomyces earlsbergensis. - Culture de 8 jours. Plage cellulaire dont la périphérie est entourée de capsules vides sous forme d'anneaux.

Fig. 2. - Candida parakrusei. - Culture de 8 jours. Capsules vides formant un réseau rigide. Souche 198.

Fig. 3. - Rhodotorula. - Souche 1.081 indéterminée. Culture de 8 jours. Même légende que pour la figure 4.

Fir. 4. - Rhodotorula. - Souche 1.081 indéterminée. Culture de 3 jours. Plages cellulaires des capsules vides et le corps cellulaire au contact de sa capsule. 
ANNALES DE PARASITOLOGIE

T. XXIII, Nos 1-2, 1948.
Planche $V$

(Mémoire Lenormand)

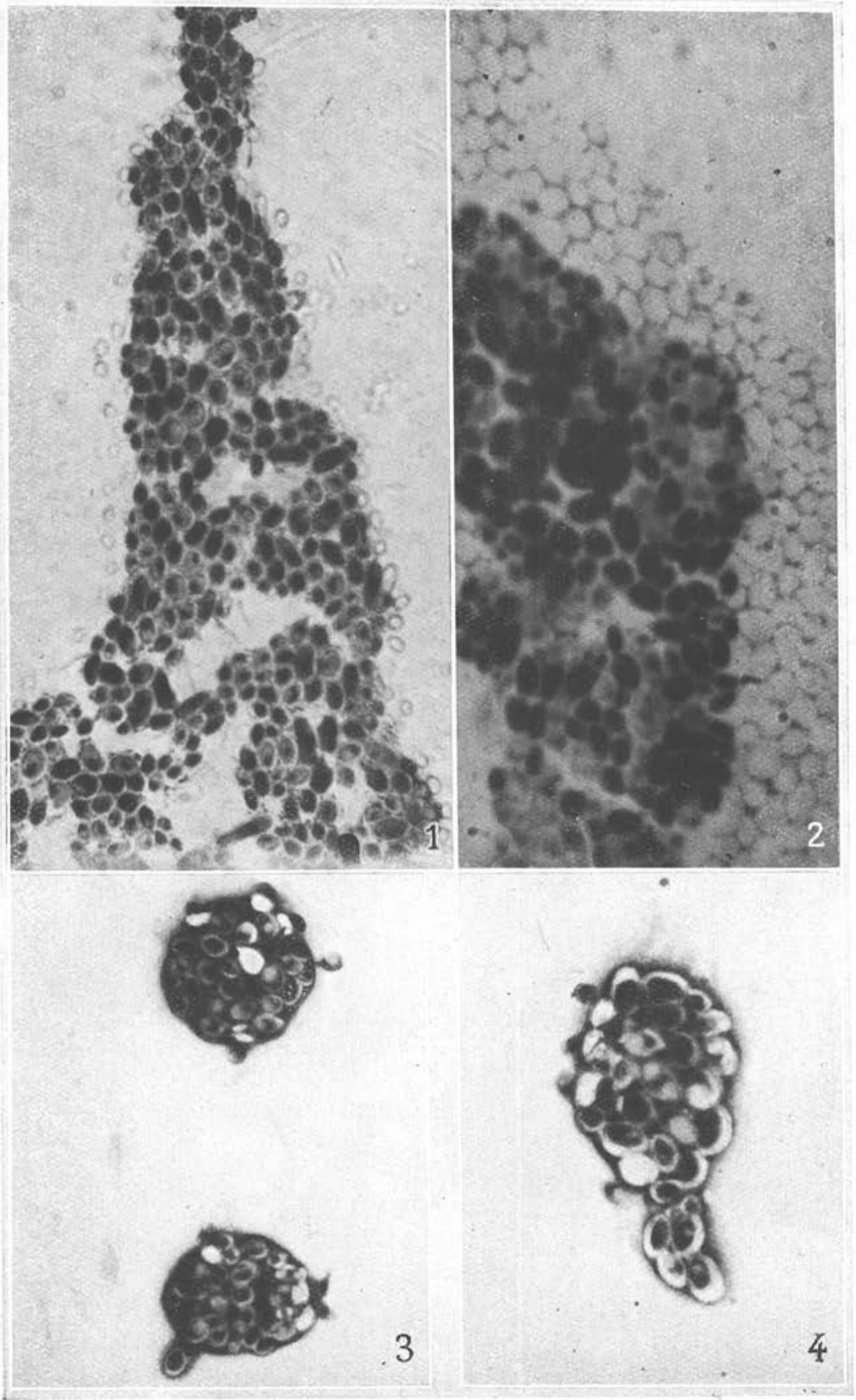

Masson et Cie, Editeurs 

Ici, les difficultés sont à peu près nulles et l'on peut dire que toutes les méthodes sont bonnes. En effet, les colorants histologiques sont plus électifs que ceux employés pour les colorations bactériologiques. Les fixations cytologiques sont aussi moins brutales. Et surtout, ces techniques ne s'exercent, en fait, que sur une seule espèce de levure, à savoir Torulopsis neoformans, la seule levure réellement pathogène pour l'homme et certains animaux de laboratoire. Cette levure a une capsule très développée en culture in vitro, mais celle-ci double ou triple son volume chez l'hôte infecté. Aussi est-il inutile de chercher une coloration spéciale, alors que les colorations les plus habituelles, telle l'hémalun-éosine, donnent de bons résultats.

Une très bonne formule est celle qui consiste à employer, après fixation par le liquide de Bouin, l'hémalun-érythrosine-safran. Avec cette coloration, la capsule de Torulopsis neoformans présente de très belles stratifications concentriques. Elle est très large, rouge vif, et séparée du corps cellulaire bleu violacé par une mince aréole incolore, paraissant vide. Le pourtour extérieur de la capsule est constitué par un liseré violet.

De l'étude de toutes ces techniques, il ressort :

$1^{\circ}$ qu'aucune d'elles n'est spécifique, permettant la coloration toujours élective de la capsule ;

$2^{\circ}$ que celles qui ont pu sembler satisfaisantes, ne le sont en fait que pour le genre Torulopsis et en particulier pour $T$. neoformans, à capsule bien développée.

Il fallait donc trouver une méthode spécifique, applicable à toutes les levures et donnant des résultats toujours semblables pour une espèce donnée. Une seule technique a répondu à ces exigences, c'est celle de Churchman et Emelianoff (1933), reprise et modifiée par Bernstein en 1941 sans résultats efficients. Cette technique sera étudiée en détail dans le chapitre suivant.

\section{IV. - MORPhologie de la CAPSUle des levures}

A. Méthode adoptée. - Contrairement aux différentes méthodes que nous venons d'envisager et dont les résultats sont souvent incertains, une méthode simple, facile à réaliser, donne de façon constante les meilleurs résultats, c'est celle qui fut décrite en 1933 par Churchman et Emelianoff.

Ces auteurs avaient cherché le moyen de mettre en évidence les 
capsules des bactéries dites « non capsulées ». Pour cela, ils employaient simultanément le colorant et le fixateur, alléguant que les fixateurs habituels (chaleur, alcool...) sont trop énergiques et modifient la morphologie bactérienne. Voici donc leur technique :

Tous leurs examens sont faits sur des cultures jeunes, de 18 heures au plus, sur milieu solide. Un fragment de la culture est émulsionné dans de l'eau distillée, étalé et séché rapidement à l'air. La préparation est alors recouverte de dix gouttes du colorant de Wright (1) filtré. On laisse au contact jusqu'à évaporation presque complète, c'est-à-dire durant trois minutes environ, le colorant étant alors de teinte pourpre. On lave ensuite avec une solution tampon de Clark et Lubbs (2) à $p \mathrm{H} 6,4$ ou 6,5 et on sèche rapidement.

Les résultats sont les suivants : le corps bactérien est bleu, la capsule est rose pourpre pâle pour sa substance, rose pourpre vif à sa périphérie.

Les meilleurs résultats sont obtenus lorsqu'on lave à l'eau distillée après l'action de la solution tampon ou quand on laisse toute la nuit la préparation dans le colorant de Wright, en évaporant ensuite comme il a déjà été dit.

Au sujet de leur méthode, les auteurs notent, d'une part, qu'une coloration trop prolongée peut nuire à la mise en évidence des capsules, et, d'autre part, que souvent il y a un dépôt de colorant sur la membrane capsulaire, celle-ci étant ainsi mieux silhouettée.

Les auteurs indiquent ensuite les modifications que l'on peut apporter à leur méthode sans nuire aux résultats. Le colorant peut

(1) Colorant de Wright, d'après Mallory (F. B.) et Wright (J. H.), Pathological Technique, $8^{\circ}$ édition, 1924.

Solution aqueuse de bicarbonate de sodium à 0,5 p. 100 ; ajouter bleu de méthylène à $1 \mathrm{gr}$. pour $100 \mathrm{~cm}^{3}$ de la solution, chauffer à 100 degrés exactement pendant une heure; dans les récipients la hauteur du liquide ne doit pas excéder $6 \mathrm{~cm}$. Refroidir dans l'eau froide si besoin est et filtrer pour éliminer le précipité. La solution refroidie doit être de couleur rouge pourpre foncé en couche mince.

A $100 \mathrm{~cm}^{3}$ de la solution filtrée, ajouter $500 \mathrm{~cm}^{3}$ d'une solution aqueuse d'éosine à 0,1 p. 100 (yellowish water soluble). Recueillir le précipité abondant sur un filtre, puis dissoudre ce précipité sec à raison de $0,1 \mathrm{gr}$. pour $60 \mathrm{~cm}^{3}$ d'alcool méthylique. Mettre en flacons. hermétiquement bouchés pour éviter l'évaporation de l'alcool.

(2) Liquide tampon de Clark et Lubbs pour un $\mathrm{pH}$ de 6,4:50 $\mathrm{cm}^{3}$ phosphate monopotassique $\mathrm{N} / 5 ; 12,6 \mathrm{~cm}^{3}$ soude $\mathrm{N} / 5$; compléter à $200 \mathrm{~cm}^{3}$.

(3) Formule du liquide de Giemsa :

Azur II éosine ........................... $3 \mathrm{gr}$.

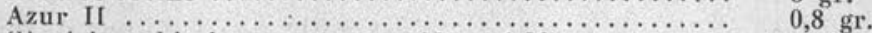

Glycérine chimiquement pure $(d=1,26) \ldots \ldots \ldots \ldots 125 \mathrm{gr}$.

Alcool méthylique chimiquement pur ............ 375 gr.

Filtrer après 48 heures de séjour à l'étuve à 37 degrès, pendant lesquelles on agite fréquemment. 
être modifié, l'érythrosine remplacer l'éosine et l'alcool éthylique se substituer à l'alcool méthylique. De bons résultats peuvent être encore obtenus avec le tétrachrome de Mac Neal, le Giemsa, la méthode de Casarès-Gill.

D'autres modifications ont été proposées par BERNŚTEIN (1941). Celui-ci, après avoir expérimenté sans résultat d'autres techniques, a adopté la méthode de Churchman et Emelianoff, mais a cru bon de la modifier afin de mieux différencier la capsule :

Il plonge deux minutes le frottis sec dans l'acide acétique à 5 p. 100, lave à l'eau et sèche avant de colorer selon la technique de Churchman et Emelianoff.

Nous-mêmes avons préféré revenir à la méthode originale ; nous avons toutefois substitué au colorant de Wright le colorant de Giemsa, dont la préparation est plus simple. Nous avions, bien entendu, vérifié l'identité des résultats donnés par ces deux colorants.

Voici la technique que nous avons adoptée :

La culture, sur gélose glycosée à 2 p. 100 , peptonée à 1 p. 100 , est émulsionnée dans une goutte d'eau distillée et étalée. Sécher rapidement, puis plonger la préparation dans un tube Borrel contenant le colorant de Giemsa pur. Laisser au contact quelques minutes. Egoutter la lame et laver rapidement avec la solution tampon de Clark et Lubbs à $p \mathrm{H} \mathrm{6,4}$. Laisser sécher et examiner avec l'objectif à immersion.

Personnellement, cette méthode nous a donné les meilleurs résultats. L'ayant essayée sur de nombreuses souches et sur plusieurs milliers de préparations, nous avons obtenu toujours les mêmes images capsulaires; images variant avec l'espèce envisagée, mais constantes pour une espèce donnée.

B. Matériel. - Grâce à l'obligeance du Centraal Bureau voor Schimmelcultures, annexe de Delft (Pays-Bas), un grand nombre de souches, de genres et d'espèces différents, ont été mis à notre disposition. L'exactitude des déterminations, nous mettant à l'abri de toute erreur diagnostique, donnait donc toute sécurité à nos recherches.

Nous avons expérimenté sur seize genres différents de levures dont voici la nomenclature exacte.

Nous les groupons en deux grandes classes:

les levures ascosporées ;

les levures anascosporées. 


\section{Levures ascosporées.}

\section{a. - Genre Saccharomyces :}

Ce groupe est important du point de vue industriel; ce sont les levures de fermentation par excellence, levures de panification, levures de vin, levures de bière, etc...

Huit espèces différentes, la plupart provenant de Delft .

Saccharomyces unisporus Jörgensen ........... $\mathrm{N}^{\circ} 95$

Saccharomyces muciparis (Beijerinck) $\ldots \ldots \ldots . . . . \mathrm{N}^{\circ} \quad 96$

Saccharomyces uvarum (Beijerinck) .......... $\mathrm{N}^{\circ} 98$

Saccharomyces pastorianus (Hansen) $\ldots \ldots \ldots \ldots \mathrm{N}^{\circ} 97$

Saccharomyces fragilis Jörgensen, 2 souches :

souche envoyée de Norvège .. $\mathrm{N}^{\circ} 998$ bEp

souche française ........... $\mathrm{N}^{\circ} 1049$

Saccharomyces carlsbergensis Hansen ......... $\mathrm{N}^{\circ} 1037$

Saccharomyces cerevisiæ (Hansen) var, annulatus $\mathrm{N}^{\circ} 402$

\section{b. - Genre Shizosaccharomyces :}

Une seule espèce:

Schizosaccharomyces octosporus Beijerinck ...... $\mathrm{N}^{\circ} 99$

c. - Genre Debaryomyces :

Trois espèces appartenant à la Mycothèque de l'Institut de Parasitologie de Paris :

Debaryomyces klöckeri Guilliermond et Peju ... $\mathrm{N}^{\circ} 603 \mathrm{~K}$

Debaryomyces hudeloi (de Beurmann et Gougerot

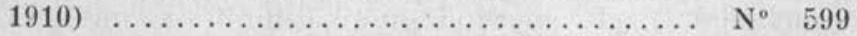

Debaryomyces matruchoti Grigoraki et Peju .... $\mathrm{N}^{\circ} 1056$

d. - Genre Pichia :

Pichia membrancefaciens Hansen .......... $\mathrm{N}^{\circ} 1038$

e. - Genre Endomycopsis :

Trois espèces envoyées de Delft :

Endomycopsis fibuliger (Lindner) Dekker ...... $\mathrm{N}^{\circ} \cdot 129$

Endomycopsis vernalis (Ludwig) Dekker ........ $\mathrm{N}^{\circ} 130$

Endomycopsis capsularis (Schiönning) Dekker .. $\quad \mathrm{N}^{\circ} 131$

\section{f. - Genre Endomyces :}

Endomyces magnusi Ludwig .............. $\mathrm{N}^{\circ} 125$

g. - Genre Hanseniaspora :

Hanseniaspora guilliermondi Pijper .......... $\mathrm{N}^{\circ} 127$

h. - Genre Hansenula :

Hansenula saturnus (Klöcker) Sydow .......... $\mathrm{N}^{\circ} 121$ 


\section{i. - Genre Nadsonia :}

Nadsonia fulvescens (Nadson et Konokotine) Sydow ..................... $\mathrm{N}^{\circ} 132$

j. - Genre Nematospora :

Nemalospora coryli (Peglion) .............. $\mathrm{N}^{\circ} 128$

k. - Genre Schwanniomyces :

Schwanniomyces occidentalis Klöcker .......... $\mathrm{N}^{\circ} 123$

\section{Levures anascosporées.}

\section{a. - Genre Torulopsis :}

Torulopsis neoformans (Sanfelice) Lodder $(=T$. histolytica).

C'est la seule levure à pouvoir pathogène élevé, et présentant une affinité particulière pour le système nerveux central.

Nous avons eu à notre disposition cinq souches de provenances différentes et numérotées comme suit :

\section{$\mathrm{N}^{\circ} \quad 859$}

$\mathrm{N}^{\circ} 858$

$\mathrm{N}^{\circ} \quad 12$

$\mathrm{N}^{\circ} 812$, souche donnée par le Prof. Debré à l'Institut de Parasitologie de Paris. Cette levure fut à l'origine d'une méningoencéphalite mortelle, dont l'étude clinique et expérimentale a paru dans le Bulletin de l'Académie de Médecine, Paris, CXXX, 1946, 443-449 et dans Annales pædiatrici, CLXVIII, 1947, 1-33.

$\mathrm{N}^{\circ} 1139$, souche issue du liquide céphalo-rachidien d'un malade mort de méningo-encéphalite et due à l'obligeance du Prof. Mollaret.

Torulopsis pulcherrima (Lindner) Saccardo ...... $\mathrm{N}^{\circ} 786$

Torulopsis laurentii (Kufferath) Lodder ........ $\mathrm{N}^{\circ} 103$

Torulopsis lipofera (den Dooren de Jong) Lodder $\mathrm{N}^{\circ} 105$

Torulopsis utilis (Henneberg) Lodder ........... $\mathrm{N}^{\circ} 104$

Torulopsis molischiana (Ziks) Lodder ........... $\mathrm{N}^{\circ} 106$

Torulopsis flavescens (Saïto) Lodder ............. $\mathrm{N}^{\circ} 107$

Torulopsis albida (Saïto) Lodder .............. $\mathrm{N}^{\circ} 108$

\section{b. - Genre Rhodotorula :}

A ce genre appartiennent les levures roses ou rouges contenant des pigments caroténoïdes :

Rhodotorula mucilaginosa (Jörgensen) .......... $\mathrm{N}^{\circ} 1080$

Rhodotorula mucilaginosa, var. carbonei Lodder $\mathrm{N}^{\circ} \quad 77$

Rhodotorula rubra (Demme) Lodder .......... $\mathrm{N}^{\circ} 79$

Rhodotorula aurantiaca (Saïto) Lodder ........ $\mathrm{N}^{\circ} \quad 80$ 


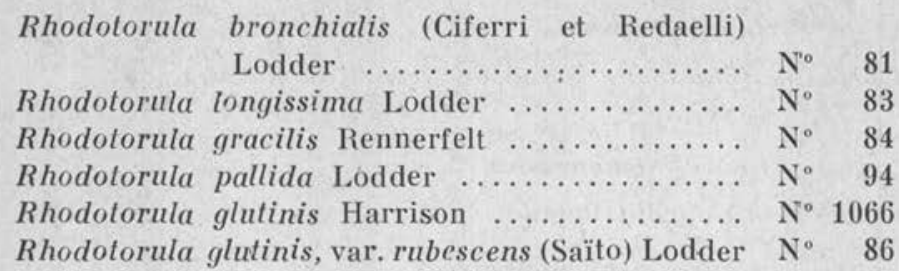

A ces dix espèces déterminées et dont la plupart sont originaires de Delft, nous ajoutons quatre souches de levures rouges, à pigments caroténoïdes, mais dont les caractères biologiques de diagnose n'entrent pas dans le cadre actuel des Rhodotorula. Ce sont les souches $\mathrm{N}^{\circ} 610$ ou souche St-Jean, $N^{\circ} 1040, N^{\circ} 1081, N^{\circ} 1069$.

\section{c. - Genre Candida}

Ce groupe présente une importance certaine du point de vue médical. En effet, parmi ses représentants on relève des espèces pathogènes pour l'homme. La virulence de ces organismes est cependant peu marquée. Elle nécessite pour se manifester un terrain spécial; le plus souvent ces levures ne déterminent des troubles que chez les organismes débilités, les cachectiques ou les infectés chroniques et, au premier chef, les tuberculeux.

Parmi tout ce groupe, il est une levure universellement reconnue pour son pouvoir pathogène, c'est Candida albicans (souvent dénommée Mycotorula albicans, ou plus improprement encore Oidium albicans). Elle est l'agent du muguet et serait à l'origine de certaines blastomycoses pulmonaires. Il n'en est rien d'ailleurs, car de nombreux prélèvements, pratiqués chez des enfants atteints de muguet, nous ont permis de constater que d'autres levures' du genre Candida devaient être incriminées.

Ce court aperçu permet néanmoins de comprendre l'importance de ce groupe en pathologie humaine.

Seize espèces ont été examinées. Ce sont :

C. albicans (Ch. Robin) Berkhout ........... $\mathrm{N}^{\circ} 118$

C. stellatoidea (Johns et Martin) Langeron et

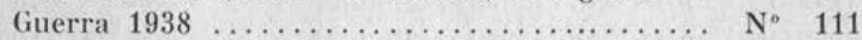

C. triadis Langeron et Talice $(1932) \ldots \ldots \ldots \ldots \mathrm{N}^{\circ}, 753$

Candida krusei (Castellani) Berkhout, souche L'Harridon ........................... $\mathrm{N}^{\circ} 1046$

Candida tropicalis (Castellani) Berkhout ......... $\mathrm{N}^{\circ} 518$

Candida parakrusei (Castellani) $[=C$. parapsilosis (Ashford) Langeron et Talice $\ldots \ldots \ldots \ldots \ldots \ldots \mathrm{N}^{\circ} 198$

Candida intermedia (Ciferri et Ashford 1929).... $\mathrm{N}^{\circ} 110$

Candida lipolytica (Harrison) Diddens et Lodder $\mathrm{N}^{\circ} 112$

Candida zeylanoüdes (Castellani) Langeron et Guerra .......................... $\mathrm{N}^{\circ} 113$ 
Candida reukaufii (Grüss) Diddens et Lodder ... $\mathrm{N}^{\circ} 114$

Candida pelliculosa (Redaelli) ..................... $\mathrm{N}^{\circ} 115$

Candida humicola (Daszewska) Diddens et Lodder $\mathrm{N}^{\circ} \quad 116$

Candida macedoniensis (Castellani et Chalmers)

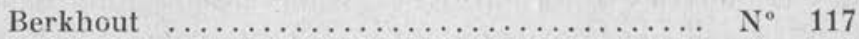

Candida brumpti Langeron et Guerra ......... $\mathrm{N}^{\circ} 119$

Candida guilliermondi (Castellani) Langeron et

Guerra ........................ $\mathrm{N}^{\text {so }} 8$ et 418

\section{d. - Genre Ashbya :}

Ashbya gossypii (Ashby et Novell) Guilliermond $\mathrm{N}^{\circ} 124$

\section{e. - Genre Mycoderma :}

Mycoderma vini Desmazières ................ $\mathrm{N}^{\circ} 126$

Telles sont les diverses souches qui ont été mises à notre disposition. Il était indispensable, pour les utiliser, d'observer certaines précautions permettant de rester toujours dans les mêmes conditions d'expérimentation.

Pour cela, toutes les souches ont été ensemencées sur gélose glycosée à 2 p. 100 , peptonée à 1 p. 100 , et maintenues à une température de 25 degrés. Les prélèvements étaient faits simultanément le même jour pour les cultures du même âge et à des âges différents de culture, mais toujours les mêmes pour toutes les souches.

Voici les temps de prélèvement choisis :

$\begin{array}{rr}\text { Cultures de } 24 \text { heures, } & \text { Cultures de } 15 \text { jours, } \\ 48 \text { heures, } & 21 \text { jours, } \\ 3 \text { jours, } & 30 \text { jours, } \\ 5 \text { jours, } & 2 \text { mois. } \\ 8 \text { jours, } & \end{array}$

C. Morphologie de la capsule. - Avant d'entreprendre la description détaillée de la capsule chez les levures, il est utile de préciser par une définition ce qu'on entend par ce terme. C'est encore Churchman et Emelianoff qui nous la fournissent :

«La capsule entoure de toutes parts le corps bactérien, elle n'est pas colorée par les méthodes habituelles, occasionnellement par le Gram et en règle seulement par des méthodes spéciales impliquant l'usage de mordants. 》

Le terme de membrane employé par Potron est le synonyme de capsule.

Parmi les auteurs qui ont le plus étudié la capsule des levures, nous retiendrons deux noms par ordre chronologique : M. Potron 
(1903) et P. Negroni (1935 et 1936). Tous deux expérimentèrent sur un petit nombre d'espèces, souvent de détermination incertaine.

Dans sa Thèse, Potron fait état :

$1^{\circ}$ des recherches antérieures de Will (1895), puis Casagrandi (1897) qui décrivaient à certains blastomycètes une membrane stratifiée, formée de couches concentriques et d'autant plus développée que la cellule est plus àgée ;

$2^{\circ}$ des travaux de Vuillemin (1900) qui différencie la membrane de Saccharomyces granulatus en deux couches, une interne stratifiée et une externe ou cuticule. Cette dernière présente une ornementation particulière, formée de tubercules situés à sa surface. Mais cette disposition n'a pu être retrouvée par Potron ni chez cet organisme, ni chez d'autres levures ;

$3^{\circ}$ enfin, l'auteur donne une description de la membrane de Saccharomyces cerevisiæ d'après Kunstlen et Busquet 1898. On verrait autour du corps de la levure trois couches différentes; en allant de la périphérie vers le centre :

$a$, une zone hyaline, claire, peu réfringente et non « tingible »;

$b$, l'enveloppe cuticulaire, résistante et réfringente, d'aspect hétérogène et présentant des alternances de couches claires et de couches sombres;

$c$, une couche sous-cuticulaire, à une seule assise, comparable à un tégument.

Malheureusement, Potron n'a pu retrouver une telle disposition.

Personnellement, Potron reprend ces recherches et étudie en particulier Torulopsis neoformans. Sa technique très simple a été décrite dans un chapitre antérieur.

Les résultats obtenus sont les suivants :

Pour les levures jeunes, la cuticule est mince, non stratifiée.

Pour les levures âgées, la membrane est très épaisse (le quart et même le tiers de l'élément considéré). Elle est striée concentriquement, avec alternance de couches claires et de couches foncées. Les strates les plus externes et les plus âgées sont souvent rompues en certains points, formant des incisures en escalier. Mais il nie l'existence d'un « halo hyalin capsulaire 》 autour des cellules, quel que soit leur âge.

La coloration par le bleu de toluidine lui permet aussi de mettre en évidence l'ornementation de la cuticule. Chez Saccharomyces tumefaciens ou neoformans, cette cuticule présente des ornementations en forme de tubercules disposés régulièrement en lignes parallèles. Ceux-ci forment la base « d'une sorte d'aiguillon acéré, 
rigide et rectiligne », atteignant exactement en hauteur la dimension de la «zone de répulsion » correspondant à la zone externe hyaline, non tingible. Il compare cette disposition des ornementations à celle d'une bogue de châtaigne. Et il conclut :

"La capsule n'est qu'une dépendance de la cuticule au point de vue de la morphologie comme au point de vue de la genèse. Elle ne ressemble en rien aux mucilages observés sur les tissus végétaux supérieurs. »

Ce même aspect en bogue de châtaigne a été retrouvé par DE Busscher, Scherer et Thomas chez Torulopsis neoformans coloré par la méthode de Nissl.

NEgRoni fait paraître en 1936 une étude sur La capsule des levures. Il emploie la méthode de coloration de Hunton et conclut qu'il existe trois groupes de levures :

a. - Celles qui forment une capsule.

b. - Celles qui produisent une substance intercellulaire.

c. - Celles qui ne produisent ni capsule, ni substance intercellulaire.

Mais la description morphologique de la capsule reste incertaine puisqu'elle se borne à ceci : " Il y a des groupes de levures dont la capsule présente des bords nets..., d'autres dont la capsule présente des limites diffuses..., finalement, il existe des levures qui ont une capsule tellement mince qu'elle se réduit à un anneau fortement coloré. »

Dans une étude antérieure (1935), il avait décrit chez Mycotorula (Candida) albicans une capsule (visible par la coloration de Hunton) stratifiée, dont les feuillets emboités les uns dans les autres pouvaient être clivés. Malheureusement, cet aspect ne fut obtenu qu'après avoir soumis les cellules de levures à des traitements plus ou moins traumatisants, tels que lavages répétés, action de la soude, du formol, du bicarbonate de sodium et du borate de sodium.

\section{RECHERCHES PERSONNELLES}

Ainsi, alors que l'étude de la capsule bactérienne a été entreprise par un grand nombre de chercheurs, les microbiologistes s'intéressèrent fort peu à la morphologie des capsules des levures. La plupart des études sont anciennes ; les descriptions données paraissent fantaisistes et beaucoup n'ont pu être vérifiées. Seuls Potron (1903) et De Busscher, Scherer et Thomas (1938), par des méthodes 
de coloration différentes, obtinrent les mêmes résultats. Malheureusement, leurs recherches restent cantonnées à un très petit nombre de levures, appartenant à deux ou trois groupes seulement.

Nous avons repris ces recherches en les étendant à un grand nombre de levures, de genres et d'espèces différents. Après des examens multiples, nous pouvons conclure que :

1) toutes les levures sont capsulées ;

2) cette capsule présente des caractères particuliers à une espèce donnée.

Nous avons d'abord envisagé :

\section{I. - LA MORPHOLOGIE gÉNÉRALE DE LA CAPSUle}

Avec la méthode de coloration de Churchman et Emelianoff, elle apparaît comme un halo plus ou moins large, rose pâle, entourant

\section{Planche VI}

Fig. 1. - Saccharomyces uvarum. - Culture de 30 jours. Aspect typique des vieilles cultures. Les cellules jeunes sont fortement colorées, alors que les cellules mortes perdent toute affinité tinctoriale et laissent seulement apercevoir la capsule vide.

Fig. 2. $\rightarrow$ Rhodotorula, - Souche 1.040 indéterminée, Culture de 30 jours Epaississements bipolaires intracapsulaires précédant le bourgeonnement somatique.

Fic. 3. - Saccharomyces cerevisia, var. annulatus. - Culture de 30 jours. Asque contenant deux ascospores avec épiplasme.

Fic. 4. - Hanseniaspora guilliermondi. - Culture de 3 jours. Deux cellules : la cellule-mère arrondie a donné naissance à une cellule-fille qui reste attachée à la cellule-mère par un filet cytoplasmique, Dans la capsule de la cellule-mère, existence d'un filament circulaire flexueux très net. De plus, la capsule présente une élevure polaire correspondant au futur point de bourgeonnement.

Fic. 5. - Rhodotorula aurantiaca, - Culture de 3 jours. Une seule cellule avec deux bourgeons très jeunes : l'un est formé seulement d'un renflement de la capsule ; l'autre est déjà habité par un prolongement intracapsulaire du soma. Souche $\mathrm{n}^{\circ} 80$.

Fig. 6. - Saccharomyces pastorianus, - Culture de 21 jours. Deux asques à trois ascospores, celles-ci, avec leur épiplasme, à cheval sur leur capsule.

FIG, 7. - Rhodotorula glutinis, var. rubescens. - Culture de 24 heures.. Ensemble de cellules ayant bourgeonné : les cellules-filles restent aecolées à la cellule-mère, dont elles sont séparées par un espace clair sans cloison. La capsule entoure tout l'ensemble. Souche $\mathrm{n}^{\circ} 86$.

Fic. 8. - Pichia membranafaciens. - Culture de 21 jours. Ascospores indiquées par une flèche. Angles dièdres capsulaires visibles. Souche $\mathrm{n}^{\circ} 1.038$,

Fig. 9. - Pichia membranefaciens. - Culture de 21 jours. Groupe d'ascospores indiquées par une flèche, avec leur épiplasme. Souche $\mathbf{n}^{\circ} 1.038$. 

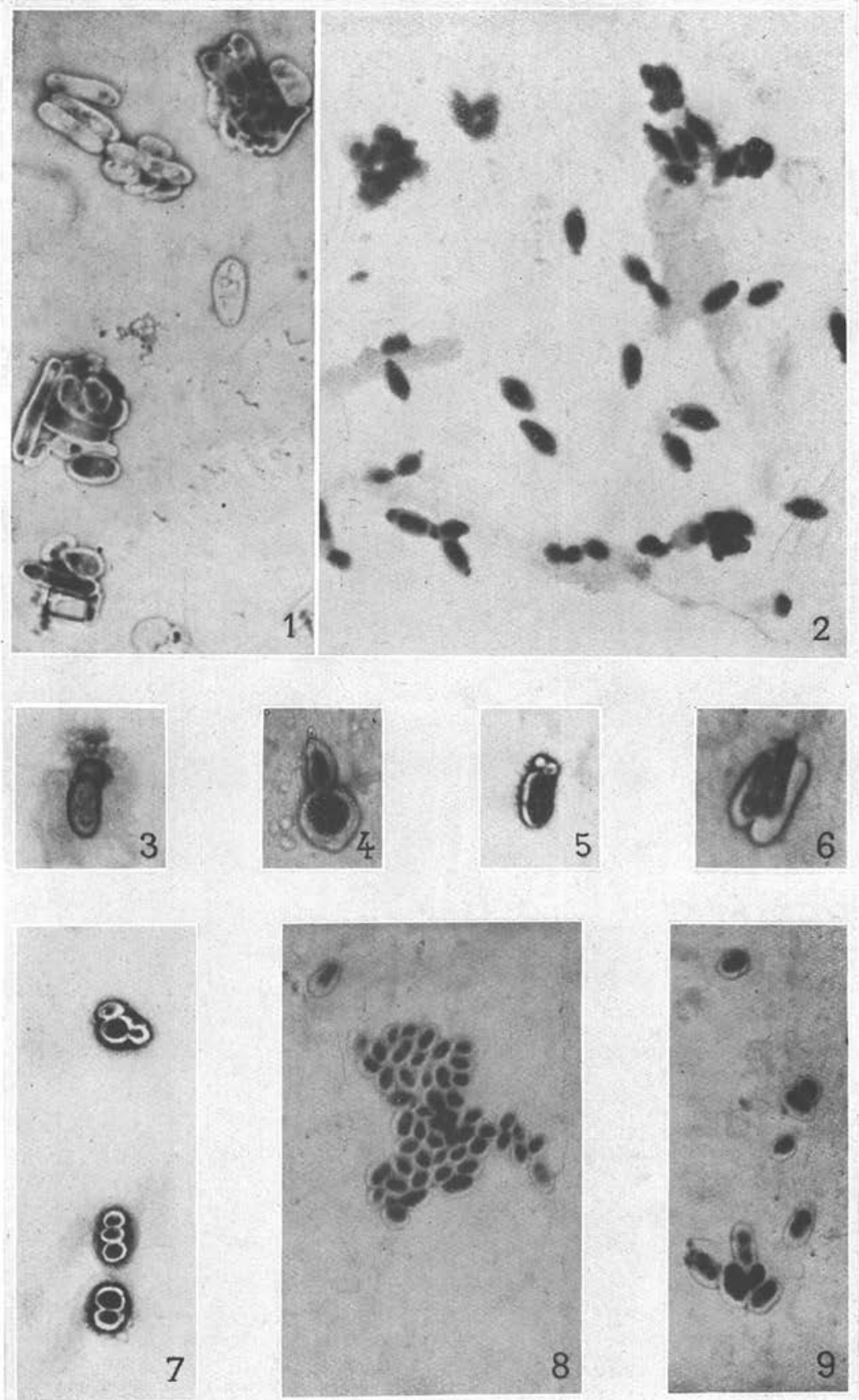

Massox et Cie, Editeurs 

de toutes parts le corps cellulaire bleu foncé et limité extérieurement par une zone linéaire très nette, fortement colorée en rouge pourpre (pl. IV, fig. 1). Cette zone linéaire externe, que l'on retrouve chez les bactéries, correspond à la cuticule capsulaire ou ectoplasme de Churchman et Emelianoff.

Lorsque les cellules sont réunies en plages, cette cuticule est surtout nette à la périphérie de la nappe cellulaire (pl. IV, fig. 1). Les cellules accolées les unes aux autres délimitent entre elles des angles dièdres, qui sont rendus très visibles par l'accumulation du colorant, sous forme d'un petit triangle ou d'un losange pourpre. L'existence d'une capsule autour de chaque élément de levure donne un aspect particulier aux plages cellulaires. Chaque cellule à soma fortement coloré est entourée d'une zone claire qui prend contact avec la zone claire ou «zone de répulsion» (Potron) d'une autre cellule. L'ensemble forme une sorte de mosaïque. Celleci est encore plus manifeste lorsqu'on examine de vieilles cultures. Les cellules en sénescence présentent un soma ou corps cellulaire qui perd peu à peu tout pouvoir tinctorial pour disparaître avec la mort de la cellule. C'est alors que l'aspect en mosaïque est le plus caractéristique ( $\mathrm{pl}$. V, fig. 2). Les cellules mortes ont complètement disparu et comme seul vestige de leur présence subsistent les capsules qui ont gardé la forme de l'ancien hôte.

Cette disposition générale se retrouve encore chez les levures qui filamentisent (comme les Candida, certains Saccharomyces, les Endomycopsis); les filaments issus des blastospores sont entourés de toutes parts d'une gaine qui présente les mêmes caractéristiques morphologique et tinctoriale que la capsule de la blastospore (pl. III, fig. 1 et 2). Dans un chapitre ultérieur, nous verrons que cette gaine n'est autre chose que la capsule même de la blastospore qui s'est étirée au point de germination, sans qu'il n'y ait jamais eu solution de continuité.

Voilà la description générale de la capsule telle qu'on la retrouve dans un grand nombre d'espèces de levures. C'est ainsi qu'elle apparait chez les genres Candida, Rhodotorula, Saccharomyces, qui sont parmi les plus connus.

A cette structure d'ensemble, la coloration fine et bien différenciée de Churchman et Emelianoff va permettre de décrire certains détails internes.

En effet, cette structure n'est pas simple. Will (1896) et CaSAGRANDI (1897) affirmaient déjà l'existence d'une stratification se manifestant par une striation concentrique, surtout sur les globules 
àgés. Cette particularité fut retrouvée par Kunstlen et BusqueT (1898) chez Saccharomyces cerevisiæ où ils décrivent une enveloppe résistante, réfringente, d'aspect hétérogène et présentant des alternances de couches claires et de couches sombres. VuilleMIN (1900) confirme cette disposition qu'il retrouve chez Saccharomyces granulatus. Les strates seraient d'autant plus nombreuses que la levure serait plus âgée. Cette même notion de stratification est encore affirmée par Negroni (1935) pour Mycotorula (Candida) albicans. Voici sa description : "La capsule, réduite à une ligne aux points de contact des cellules, grossit vers les côtés en se décomposant par occasion (spécialement après avoir lavé avec de l'eau) en une série de feuillets stratifiés, comme s'il s'opérait un clivage. Parfois, elle éclate et il persiste, collés au pôle de cellules, des restes filamenteux en franges... » Une photographie vient concrétiser cette description. Negroni, toutefois, déclare que l'aspect normal de la capsule est d'être figurée par un ectoplasme linéaire et que l'apparition des stratifications pourrait être due à un artifice de préparation.

L'existence de cette architecture interne de la capsule a donc été établie par la plupart des auteurs et nous-mêmes ne saurions la nier. Nous l'avons retrouvée cependant assez rarement; elle ne paraìt pas l'apanage d'un genre de levure donné, permettant de le caractériser, mais semble appartenir à la structure capsulaire en général. Nous avons pu la mettre en évidence dans des groupes de levures très divers que nous réunissons dans le tableau suivant :

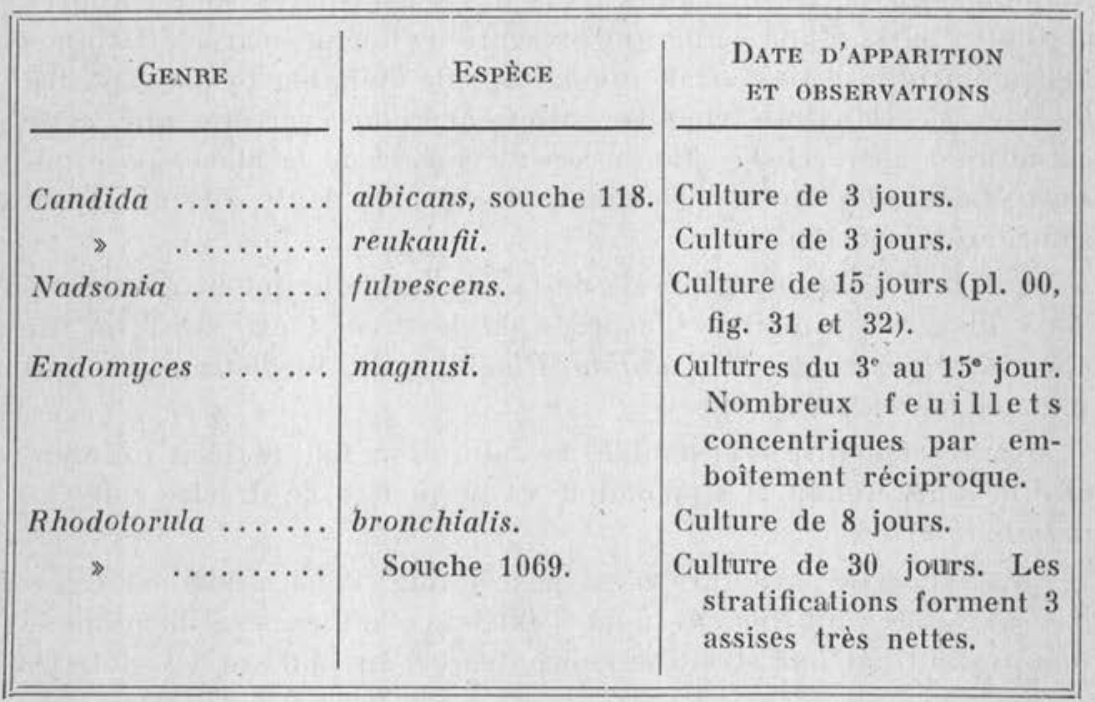


La capsule, alors particulièrement développée, présente des alternances de zones sombres et de zones claires, donnant une impression de stries concentriques par emboitement réciproque. Leur apparition est indépendante de l'âge de la culture, on les retrouve aussi bien dans des cultures jeunes, de trois jours, que dans des cultures plus âgées, de trente jours. Le nombre de stratifications paraît aussi peu influencé par l'âge. Enfin, fait particulier, cette striation circulaire persiste après la mort de la cellule, alors même que le soma a disparu. Cette image fut observée sur une préparation d'une culture au huitième jour de Rhodotorula bronchialis ; la capsule, vide de son soma, présentait ses deux parois interne et externe colorées en rose, avec quelques stries entre elles deux.

Cet aspect architectural ne peut donc plus être mis en question ; mais, fait particulier et encore inédit, semble-t-il, la capsule nous a paru posséder une architecture interne beaucoup plus variée et très curieuse.

C'est ainsi que nous avons pu mettre en évidence les aspects suivants :

$1^{\circ}$ Au sein même de la capsule, se dessine chez certaines levures une formation linéaire, flexueuse, entourant le soma cellulaire de toutes parts, mais ne prenant jamais contact ni avec ce dernier, ni avec l'ectoplasme capsulaire. On a done l'image d'un anneau plus ou moins flexueux. La réaction tinctoriale est celle de l'ectoplasme capsulaire lui-même. Cette ligne divise alors la capsule en deux parties présentant inconstamment des réactions tinctoriales différentes : la zone interne périsomatique reste incolore, tandis que la zone externe prend une teinte rose pâle.

Cet aspect semble fréquent, nous l'avons retrouvé dans un grand nombre d'espèces (tableau de la p. 84).

La signification de cette formation linéaire nous échappe, mais l'ébauche d'autres lignes semblables, plus ou moins complètes, donne à certaines levures un aspect stratifié assez net (pl. VII, fig. 2), différent cependant de celui décrit précédemment où les stratifications nous apparaissaient comme des zones contrastées par opposition de réfringence.

$2^{\circ}$ Au sein même de la capsule, des formations linéaires très particulières coexistent d'ailleurs très souvent avec celles précédemment décrites. La fig. 2 (pl. VII) d'une préparation d'une culture au troisième jour d'Endomycopsis capsularis objective bien cette architecture. De la paroi externe de la capsule, partent des filaments, à même réaction tinctoriale que l'ectoplasme lui-même; ils s'incurvent, se rejoignent, formant des sortes d'arcades dont les 


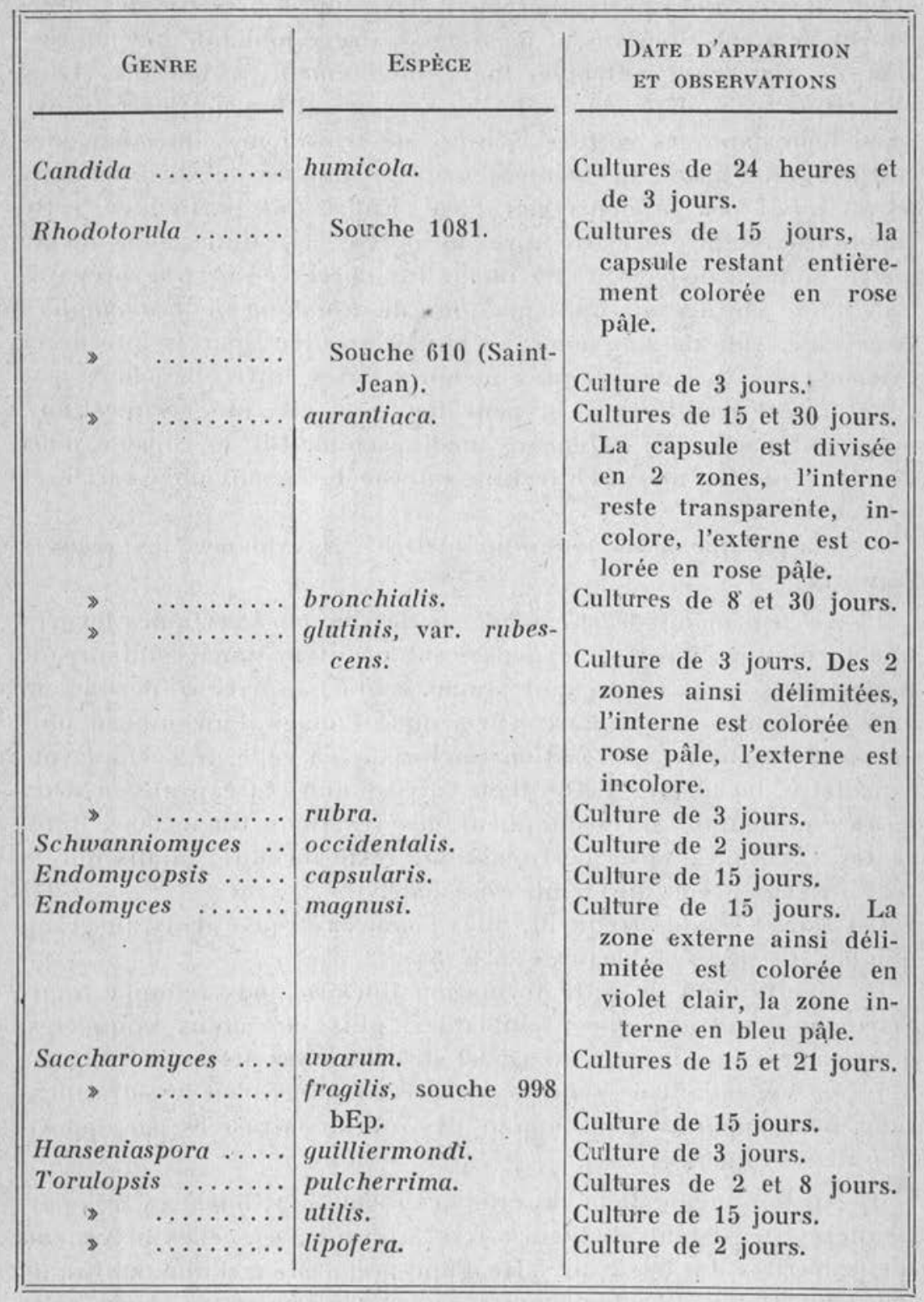

clés de voûte n'ont aucun point de contact avec le soma. Le plus souvent, une fraction de la circonférence capsulaire est occupée par 
ces arcades qui n'excèdent guère le nombre de cinq ou six. L'autre fraction, libre, est alors fréquemment parcourue par la formation linéaire déjà décrite. La netteté de ces images n'est pas toujours aussi absolue et se réduit à des prolongements qui rejoignent l'ectoplasme à la ligne intracapsulaire.

Voici les espèces chez lesquelles nous avons retrouvé ces images :

\begin{tabular}{|c|c|c|}
\hline Genre & EsPĖcE & $\begin{array}{l}\text { DATE D'APPARITION } \\
\text { ET OBSERVATIONS }\end{array}$ \\
\hline $\begin{array}{r}\text { Rhodotorula } \ldots \ldots \ldots \\
\quad \ldots \ldots \ldots\end{array}$ & $\begin{array}{l}\text { capsularis. } \\
\text { Souche } 1.069 \text {. } \\
\text { mucilaginosa. }\end{array}$ & $\begin{array}{l}\text { Culture de } 3 \text { jours. Image } \\
\text { reproduite dans la photo } \\
n^{\circ} 2 \text {, pl. VII. Ces images } \\
\text { se retrouvent dans les } \\
\text { cultures de } 8 \text { et de } 15 \\
\text { jours. } \\
\text { Culture de } 24 \text { heures. } \\
\text { Culture de } 24 \text { heures. Chez } \\
\text { ces deux souches les ar- } \\
\text { cades sont moins nettes. } \\
\text { L'anneau intracapsulai- } \\
\text { re donne des prolonge- } \\
\text { me n } t \mathrm{~s} \text { q i prennent } \\
\text { contact avec l'ectoplas- } \\
\text { me. }\end{array}$ \\
\hline
\end{tabular}

$3^{\circ}$ Chez quelques levures, et en particulier les genres Torulopsis et Rhodotorula, nous avons observé des images très curieuses. L'intérieur de la capsule est occupé par de nombreux grains rouges, équidistants et régulièrement répartis sur une ligne circulaire située à peu près à égale distance entre le corps cellulaire et la limite externe de la capsule. C'est l'image assez parfaite d'une couronne. De ces granulations, partent de nombreux filaments rouges, flexueux, se dirigeant soit vers l'ectoplasme, soit vers le corps cellulaire. La photographie $\mathrm{n}^{\circ} 3$, pl. VIII d'une culture de cinq jours de Torulopsis lipofera montre cette couronne, et l'on devine les filaments qui en partent. Ces images, difficiles à rendre par la photographie, sont en fait d'une grande netteté au microscope, car leur couleur rouge vif contraste sur le fond absolument transparent de la capsule. 
Nous les avons obsiervé chez:

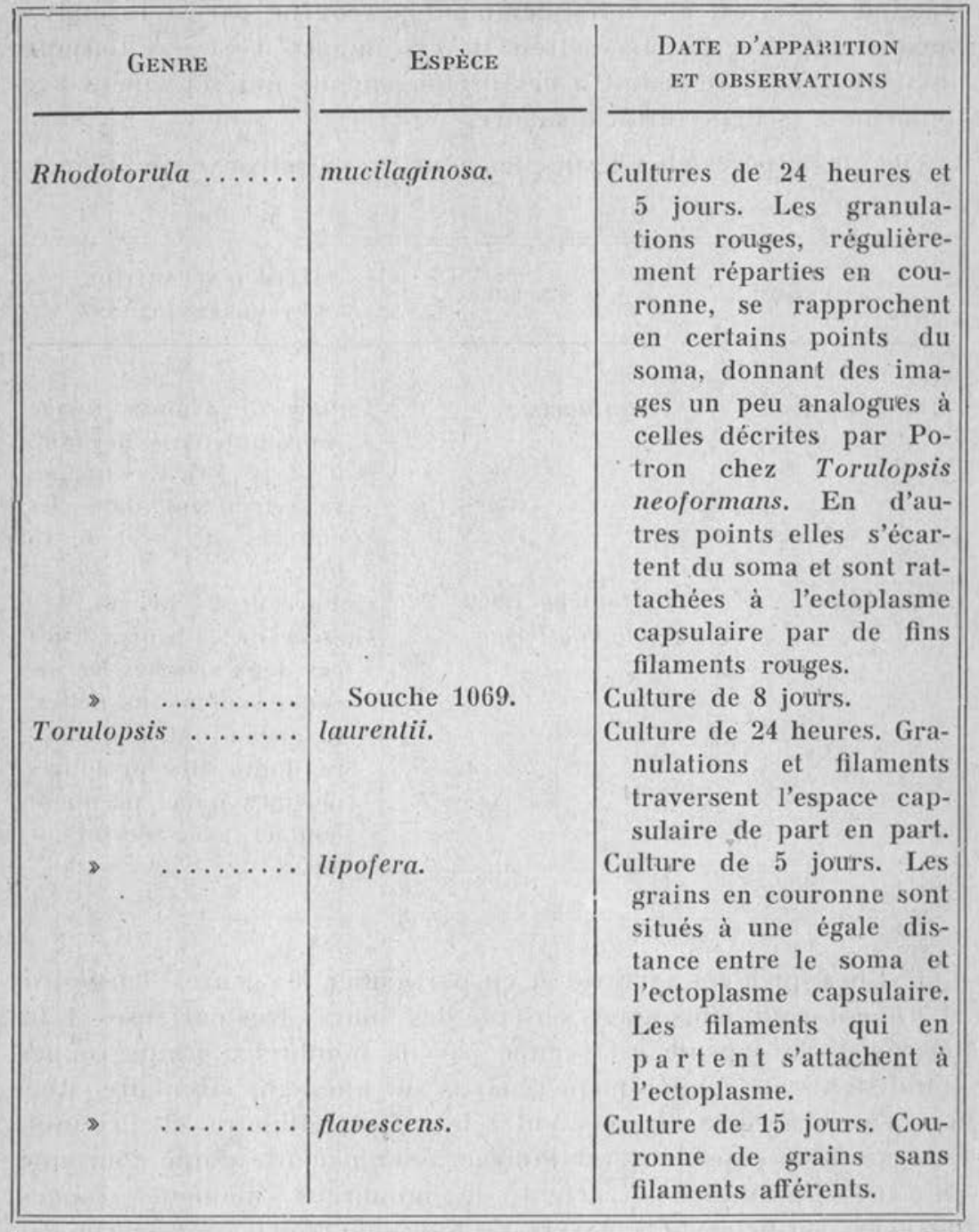

Que ce soient formations en arcades ou couronnes de grains, ces images n'apparaissent que dans les cultures jeunes, de un à cinq jours, et, pour une seule souche, Torulopsis flavescens, elles persistaient au quinzième jour de culture.

Nous ne pensons pas que ces formations soient un artifice de préparation, nous les avons retrouvées à maints examens de cultures de même âge, et leur aspect était toujours semblable, même 
situation intracapsulaire, même union avec l'ectoplasme par de fins filaments.

Nous n'avons pas encore parlé des limites mêmes de la capsule.

$1^{\circ}$ La limite externe ou ectoplasme est toujours visible, elle se colore en rouge violacé plus ou moins intense. Elle apparaît soit sous forme d'une ligne circulaire continue et homogène et c'est le cas le plus fréquent, soit sous forme d'une juxtaposition linéaire de granulations rouges plus ou moins volumineuses selon les cas, le colorant ayant été comme attiré et retenu par la capsule, peut-être par un phénomène de tension superficielle. Très souvent, l'ectoplasme capsulaire est alors entouré d'une zone réticulée rouge.

Le tableau ci-dessous indique les levures chez lesquelles nous avons vu cette disposition granuleuse de l'ectoplasme:

\begin{tabular}{|c|c|c|}
\hline Genre & EsPĖCE & $\begin{array}{l}\text { DATE D'APPARITION } \\
\text { ET OBSERVATIONS }\end{array}$ \\
\hline 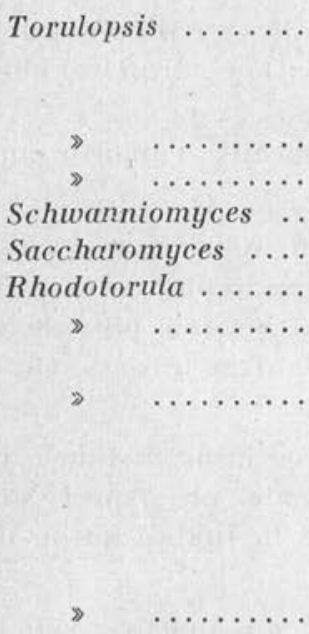 & $\begin{array}{l}\text { neoformans, souche } \\
\mathrm{n}^{\circ} 12 . \\
\text { Souche } \mathrm{n}^{\circ} 812 \text {. } \\
\text { flavescens. } \\
\text { albida. } \\
\text { occidentalis. } \\
\text { muciparis. } \\
\text { aurantiaca. } \\
\text { Souche } 610 \text { (Saint- } \\
\text { Jean). } \\
\text { Souche } 1069 . \\
\\
\text { humicola. }\end{array}$ & $\begin{array}{l}\text { Culture de } 24 \text { heures. } \\
\text { Cultures de } 24 \text { et } 48 \text { h. } \\
\text { Culture de } 3 \text { jours. } \\
\text { Culture de } 2 \text { jours. } \\
\text { Culture de } 2 \text { jours. } \\
\text { Culture de } 24 \text { heures. } \\
\text { Culture de } 30 \text { jours. } \\
\text { Culture de } 8 \text { jours. L'ec- } \\
\text { toplasme e st formé, } \\
\text { pour certaines capsules, } \\
\text { de grains accolés dis- } \\
\text { posés en plusieurs cou- } \\
\text { ches. } \\
\text { Culture de } 24 \text { heures. }\end{array}$ \\
\hline
\end{tabular}

$2^{\circ}$ La limite interne est plus difficile à mettre en évidence. Elle est le plus souvent linéaire; dans un cas seulement (Torulopsis laurentii), nous l'avons vu formée par la juxtaposition de granulations. Sa réaction tinctoriale est celle du bord externe de la capsule. Sa difficulté de visibilité est due au fait qu'elle est accolée au soma et seule la disparition du corps cellulaire laisse apparaitre ce bord 
(pl. VIII, fig. 1). Cependant, dans certains groupes de levures, et en particulier chez les Torulopsis, son existence est indéniable, sa visibilité parfaite, puisque la capsule est toujours séparée du corps cellulaire par un espace libre entourant celui-ci à la façon d'un anneau de Saturne.

\section{II. - Morphologie particulière aux tORULOPSIS}

Cette description détaillée de la capsule ne saurait être complète si nous n'envisagions le 'genre Torulopsis, dont la morphologie capsulaire est bien particulière, à tel point qu'elle permet à elle seule le diagnostic du genre et dans certains cas de l'espèce elle-même.

Ce genre revêt une grande importance en pathologie humaine. Les méningo-encéphalites à Torulopsis neoformans (= histolytica) sont connues et redoutées des praticiens. Nombreuses sont les publications cliniques sur son pouvoir pathogène, les études histologiques sur son aspect dans les tissus. Peu d'auteurs ont étudié sa capsule dans les milieux de culture. Cependant, Potron (1903) et DE Busscher, Scherer et Thomas (1938), par des méthodes différentes, trouvèrent les mêmes aspects de striations transversales rigides, semblables à des piquants.

L'examen de nombreuses souches nous a permis d'aboutir aux résultats suivants :

Dans le milieu de culture glycosé à 2 p. 100 , tous les représentants du genre Torulopsis étudiés par nous présentent une capsule très importante. Sa taille est souvent deux ou trois fois plus développée que celle des plus grandes capsules des autres levures. On y distingue :

1. - Un bord interne toujours situé à une certaine distance du corps cellulaire. Il se colore en rouge et présente un aspect soit linéaire, uniforme, soit irrégulier, formé par la juxtaposition de grains rouges.

2. - Un bord externe ou ectoplasme, rouge, soit linéaire, soit le plus souvent composé de granulations rouges, accolées les unes à côté des autres sur un seul rang.

L'ensemble de la levure donne l'aspect suivant : un centre, formé par le corps cellulaire, globoïde, coloré en bleu violacé, entouré de toutes parts par un large anneau rose, celui-ci laissant toujours un espace libre entre lui et le corps cellulaire. Cet anneau est souvent très large et peut atteindre en largeur deux fois la taille du soma. 
Cet aspect n'est visible que dans les cultures jeunes, jusqu'au cinquième jour environ ; lorsque la culture vieillit, l'espace libre entre soma et capsule diminue et le bord interne de la capsule tend à s'accoler au soma. Il n'est alors plus possible de le voir, et il n'apparaît que chez les levures mortes ou à capsules déshabitées (pl. VIII, fig. 1). Le bord externe se continue souvent, lorsqu'il est formé de grains juxtaposés, par une zone d'étendue variable, finement réticulée et se colorant en rouge comme l'ectoplasme.

3. - A l'intérieur de la capsule, les images sont variées. On y retrouve les formations linéaires déjà décrites, mais surtout, et avec la plus grande netteté, la capsule présente une couronne formée de grains juxtaposés et qui constituent le point de départ de nombreux filaments traversant la capsule de part en part. La fig. 3, pl. VIII, illustre cet aspect.

Dans d'autres espèces, telles Torulopsis laurentii et $T$. albida, la capsule est finement réticulée, sans qu'on puisse y découvrir de relais granuleux (pl. VIII, fig. 8).

Mais c'est $T$. neoformans qui présente l'architecture capsulaire la plus particulière. Potron (1903), après coloration d'une émulsion de culture par le bleu de toluidine, en solution aqueuse concentrée, décrit ainsi la capsule : "La cuticule est loin d'être lisse. Elle offre de petits tubercules disposés de façon régulière en lignes parallèles... A un degré plus avancé de coloration, on s'aperçoit que chacun des petits tubercules n'est que la base d'une sorte d'aiguillon acéré, coloré en violet pâle, rigide et rectiligne, atteignant exactement en hauteur la dimension de la zone de répulsion que nous signalions au début... Ainsi donc, loin d'être nu, ce blastomycète possède un revêtement très spécial qui rappelle celui des fruits du châtaignier et l'on ne peut mieux comparer la quantité de «piquants» qui l'ornent qu'à celle qui hérisse la surface de la châtaigne. »

Les mêmes images furent retrouvées par de Busscher, Scherer et Thомas (1938) qui employèrent la coloration de Nissl.

Nous avons repris ces différentes méthodes avec un inégal succès. Jamais par la méthode de Nissl, avec emploi de la thionine à 1 p. 100, nous n'avons pu mettre en évidence les images décrites par les auteurs. Nous avons été plus heureux avec la coloration au bleu de toluidine à 1 p. 100 : nous avons d'une part retrouvé les images en bogue de châtaigne décrites par POTRoN et, d'autre part, un aspect assez curieux que nous ne saurions mieux comparer qu'à un œuf humain embryonné, de un mois et demi, époque où il est entièrement recouvert de villosités choriales. En effet, l'aspect est le sui- 
vant : le corps cellulaire est entièrement entouré d'un fin chevelu de filaments colorés en rouge, flexueux et qui occupent toute l'épaisseur de la capsule, l'ectoplasme capsulaire formant leur limite en dehors. Malheureusement, opérant en milieu liquide, nous n'avons pu photographier ces images, car notre appareil nécessite l'inclinaison du microseope. Lorsqu'on modifie la méthode de Nissl, en remplaçant le bleu polychrome de Unna par le bleu de toluidine, et le différenciateur de de Gothard par l'eau acétifiée à 1 p. 500 , on obtient à peu près les mêmes images. C'est par la coloration au Giemsa que nous avons obtenu les plus belles figures. La fig. 5 (pl. VIII) d'une culture de deux jours de Torulopsis neoformans (souche 858) illustre eet aspect. Potron, qui malheureusement ne donne aucune photographie des images décrites, a dessiné quelques schémas explicatifs. Les « piquants » partent de la membrane même du soma et, rectilignes, aboutissent à la limite externe de la capsule. Sur nos préparations, ces striations n'ont aucun point de contact avec le corps cellulaire, elles partent du bord interne capsulaire qui, de ce fait, parait dense, épais et fortement coloré, et se dirigent en rectitude vers le bord externe de la capsule.

Cette disposition capsulaire, propre à $T$. neoformans, permet à elle seule le diagnostic de l'espèce. On ne la retrouve dans aucune autre espèce du genre Torulopsis, ni d'aucun autre genre.

\section{III. - Discussion}

Après une aussi longue description, il nous parait difficile de mettre en doute l'existence même de la capsule. Elle ne peut être un artifice parce que :

1. - Par d'autres méthodes que celle adoptée dans notre étude, nous obtenons les mêmes images capsulaires.

\section{Planche VII}

Fic, 1. - Torulopsis neoformans. - Culture première examince en Lugol. Aspect réticulé de la capsule bien développée. Cas Ducuing, Toulouse. Souche $n^{\circ} .632$.

Fig. 2. - Endomycopsis capsularis, - Culture de 3 jours. Plage cellulaire avec, à la périphérie, une capsule très développée et présentant des stratifications plus ou moins sinueuses. Souche 131.

Fig. 3. - Agrandissement de la fig. 2, montrant les arcades et les lignes intracapsulaires.

Fig. 4. - Torulopsis neoformans. - Coupe de torulose expérimentale du cobaye, cas Bablet et Genevray. Coloration par l'hémalun-érythrosine-safran. Belles stratifications. 
ANNALES DE PARASITOLOGIE

T. XXIII, Nos 1-2, 1948.

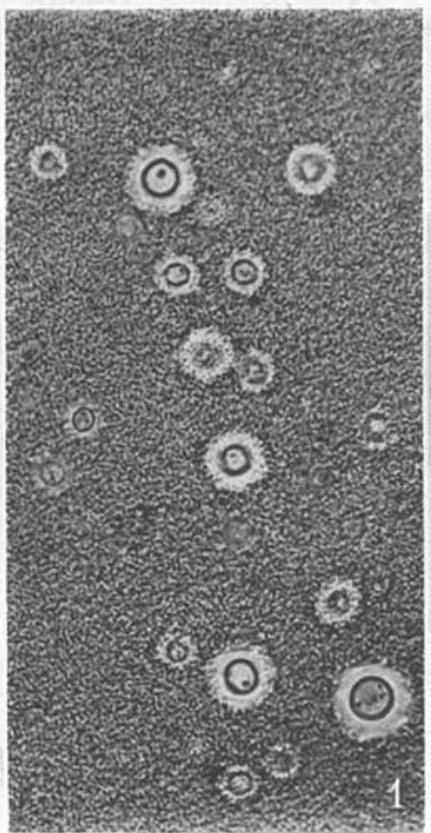

Planche VII

(Mémoire Lenomand)
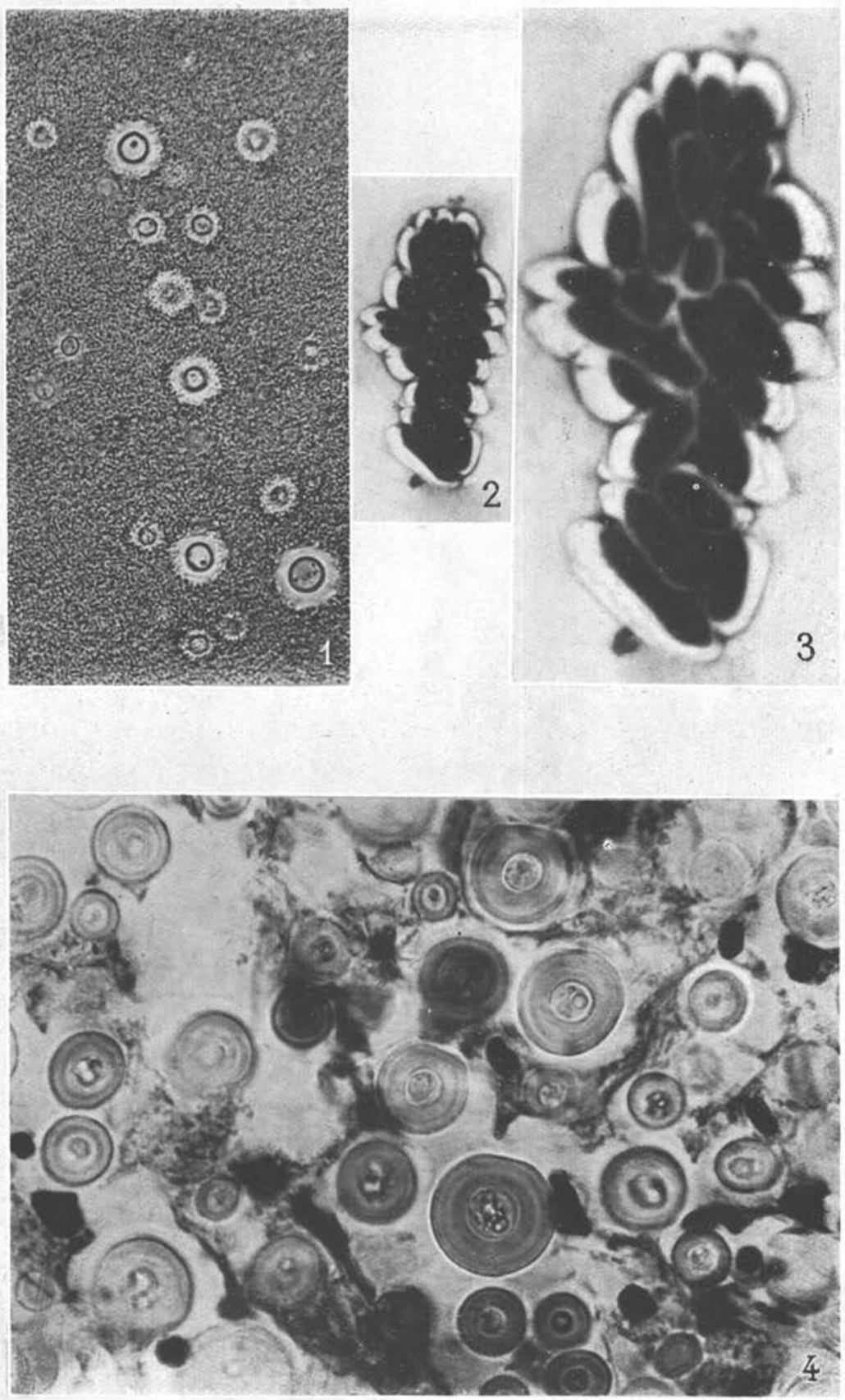

Masson et Cie, Editeurs 

2. - La capsule se colore d'une manière différente du corps cellulaire.

3. - Les différentes images intracapsulaires que nous avons décrites ont été retrouvées à maints examens de souches d'âges différents. Lors de ces examens, nous les avons revues, toujours avec le même aspect que chez les seules souches où nous les avons décrites. Dans d'autres genres, où nous les avons cherchées maintes fois, il ne nous a pas été possible de les découvrir.

4. - La capsule épouse le plus souvent la forme exacte du corps cellulaire ; cependant, dans certaines espèces, lors du bourgeonnement, elle subit une transformation qui lui est propre et qui précède toute division du corps cellulaire. Elle peut aussi présenter des irrégularités ne correspondant nullement à des images semblables du soma.

5. - Fait particulier, qui à lui seul permet de ne pas mettre en doute l'existence de la capsule, celle-ci donne une impression remarquable de rigidité. Bernstein (1941) en avait été frappé pour la capsule du bacille de Neisser. Les aspects en mosaïque illustrent ce fait (pl. V, fig. 2). En effet, lorsque les cellules sont mortes, le corps disparaît, mais la capsule reste longtemps intacte, reproduisant la forme primitive du soma disparu.

Par ailleurs, il est fréquent de voir le corps cellulaire expulsé pendant la coloration hors de la capsule ; il est alors soit à cheval sur le cadre rigide de celle-ci, soit à une certaine distance d'elle, étant alors absolument nu, sans aucune trace de capsule, pl. V, fig. 3 , 4 et pl. VI, fig. 6,28 ). A un moindre degré, on trouve le soma excentré à l'intérieur de la capsule.

Lorsque les cellules sont réunies en plages, l'aspect le plus fréquent est celui-ci : chaque cellule s'accole à sa voisine par le bord externe de sa capsule, ces deux bords superposés donnent une impression de surépaisseur, le contact cesse aux pòles où le colorant est retenu, donnant des images en losange, en triangle. Parfois, il n'en est pas ainsi, l'ectoplasme capsulaire n'étant plus parfaitement rectiligne, l'accolement se fait mal et il est très facile de voir les bords de deux cellules voisines, côte à côte, mais non confondus. Lorsque plusieurs cellules s'accolent, elles laissent alors entre elles un espace angulaire assez considérable pour que le colorant ne s'y accumule pas. Cet espace est alors libre et l'on peut suivre l'ectoplasme respectif des cellules qui le limitent.

6. - Cette capsule est bien individualisée, puisque le corps cellulaire peut se diviser en son sein, s'accroitre, la cellule fille s'isoler de la cellule mère, sans qu'en aucun cas la capsule se soit rompue. 
Elle s'étrangle seulement au niveau de la zone de séparation entre les deux cellules. Parfois même, plusieurs cellules issues de divisions successives restent incluses dans une capsule commune.

\section{III. - Modifications de LA CAPSUle sous difFérentes ACtions}

Contrairement à une opinion ancienne, la capsule est d'emblée bien développée, sa taille croît environ jusqu'au huitième jour de culture, puis elle reste stationnaire. \& L'encapsulation est essentiellement un phénomène de la période de croissance logarithmique.»(Morison, 1940). Dans les très vieilles cultures, de deux mois et plus, la capsule reste bien visible, alors que très souvent le corps cellulaire a disparu.

Par contre, les figures de stratifications par emboitement réciproque se voient surtout dans les cultures jeunes, avec le maximum de fréquence les trois premiers jours.

Les milieux de culture influencent peu la taille de la capsule. Cependant, nous avons pu constater une nette diminution sur milieu P.C. (pomme de terre-carotte), sur le milieu de conservation de Sabouraud. Sur eau de pomme de terre, nous avons obtenu de belles capsules stratifiées avec Torulopsis neoformans, au bout de cinq semaines seulement, alors que dans les cultures jeunes, elles étaient réduites à une simple aréole entourant le corps cellulaire.

Par contre, sur milieux sucrés, la capsule se développe bien. Les hydrates de carbone qui ont donné les meilleurs résultats sont le glycose, le maltose, le saccharose, le galactose, le lactose, tous sucres bien assimilés par les levures.

Mais c'est surtout sur les milieux riches en substancies azotées que l'on obtient les plus belles capsules. Nous avons cultivé nos souches sur gélose glycosée à 2 p. 100 , peptonée à 1 p. 100 , additionnée successivement de sulfate d'ammonium, nitrate de potassium, nitrate de sodium, nitrate de magnésium, phosphate d'ammonium, dans la proportion de un milligramme par centimètre cube. Dans tous les cas, les capsules étaient bien développées. Un milieu nous a donné les meilleurs résultats, c'est le milieu de CzapeckDox (1).

(1) Formule du milieu de Czapek-Dox :

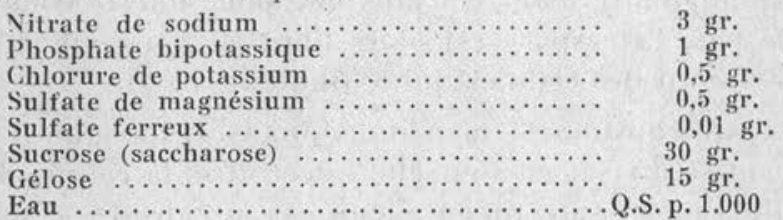


En résumé, la capsule se développe bien sur tout milieu riche où la multiplication cellulaire se fait vite.

Enfin, nous rappellerons que la capsule est tout particulièrement développée lorsque la levure végète au sein d'un tissu animal. Sa taille peut alors être le triple ou le quadruple de eelle du corps cellulaire. Torulopsis neoformans est un bel exemple de ce fait. Examinés dans le liquide céphalo-rachidien d'un sujet atteint de torulose ou chez l'animal infecté, les globules de levure sont entourés d'une énorme capsule réfringente, stratifiée.

Nombreux sont les auteurs qui ont noté la résistance particulière de la capsule aux agents chimiques. Seuls les acides et bases forts l'altèrent (Dubos, 1946). NEGRoNi (1936) a soumis sans succès la capsule de Candida albicans à six lavages successifs à l'eau distillée, à des lavages avec une solution à 2 p. 100 de borate et de bicarbonate de sodium, à l'action de solutions respectivement de 0,1 p. 100 , 0,33 p. $100,0,5$ p. 100 de soude. La levure, mise au contact pendant 24 heures d'une solution à 0,5 p. 100 de formol (à 40 p. 100) ou de cinq volumes d'alcool-acétate (alcool à 96 degrés avec 13 p. 100 d'acétate de sodium), conserve encore après lavage à l'eau distillée une capsule intacte. Il faut atteindre des concentrations de 1 à 2 p. 100 de soude pour la détruire. Cependant, des solutions à 10 p. 100 de borate ou de bicarbonate de sodium modifient la morphologie capsulaire ; NEgroni a vu alors la capsule de Candida albicans se dissocier en une série de lamelles stratifiées.

IV. - RAPPORTS DE LA CAPSULE ET DU BOURGEONNEMENT CELLULAIRE

L'étude du processus de multiplication des levures va nous arrêter un certain temps, à cause des modifications qu'il imprime à la capsule.

Le mode de multiplication asexuée des blastomycètes est le bourgeonnement, soit qu'il aboutisse à un élément fille analogue à la cellule mère par sa forme et ses caractères biologiques, soit qu'il y ait production d'un pseudo-mycélium à partir d'une blastospore.

Le plus généralement, la capsule se soulève en un point, en même temps que le soma présente une élevure. Celle-ci grandit peu à peu, se renfle; sa base d'implantation sur la cellule mère devient de plus en plus mince. Pendant cette croissance, la capsule de la cellule mère s'étire sous la poussée du bourgeon, qu'elle entoure toujours étroitement. Puis lors de la séparation entre les deux cellules, la rupture se fait d'abord au niveau du soma. Une cloison d'origine 
capsulaire se forme alors et elle se clivera pour libérer les deux cellules. Lorsque la séparation s'est opérée, il ne reste aucune trace du phénomène.

Ceci est contraire aux assertions de Potron qui admet une rupture de la cuticule : «...Le jeune globule en formation ne possède pour tunique que la strate la plus interne et la plus mince du globule maternel; les autres couches externes, moins élastiques, se rompent et constituent au eollet du bourgeon une sorte de collerette au travers de laquelle il sort. » Après la chute du bourgeon, il persisterait une cicatrice ombiliquée sur le globule maternel. En aucun cas, nous n'avons observé pareils faits.

Dans le cas où la cellule fille reste unie à la cellule mère, le cloisonnement décrit plus haut ne se produit pas, la capsule s'étrangle seulement entre les deux cellules. Dans d'autres cas encore, les somas se divisent tout en restant inclus dans la capsule, qui s'étire au fur et à mesure des divisions cellulaires, sans émettre de cloisons intercalaires (pl. VI, fig. 7).

Ce mode de bourgeonnement est le plus général, on le retrouve dans tous les genres et chez toutes les espèces de levures. C'est le mode classique par excellence, mais aucun auteur n'a encore jamais décrit le comportement capsulaire vis-à-vis des cellules et de leurs bourgeons. Qu'il y ait un ou plusieurs bourgeons, le processus est d'ailleurs le même.

Chez quelques espèces, à còté du mode habituel de bourgeonnement, nous avons observé des manifestations plus complexes, dont nous n'avons retrouvé aucune relation dans la littérature. Lorsque le bourgeonnement va se produire, la capsule est le siège de phénomènes bien particuliers. En un pôle de la cellule, et souvent aux deux pôles diamétralement opposés, la capsule subit un épaississement important, qui se traduit par une bande transversale, allant de part en part du soma à la cuticule, fortement colorée comme l'ectoplasme capsulaire. Lorsque les deux pôles sont épaissis, la levure, le plus souvent ovalaire, ressemble assez bien à un œuf de trichocéphale (pl. VI, fig. 2).

Cet épaississement se creuse bientôt en un étroit canal. C'est alors seulement que le soma émet une fine expansion protoplasmique qui s'engage dans le pertuis capsulaire. L'ectoplasme, qui limite le pertuis en dehors, se soulève; le bourgeon, à sa sortie du canal se renfle, se coiffe de l'ectoplasme et lorsqu'il atteint une certaine taille, se détache de la cellule mère ; le pertuis se comble, mais l'épaississement persiste longtemps.

Nous avons observé ce phénomène chez quelques Rhodotorula, un Hanseniaspora. 
Chez les Torulopsis, ce mode de bourgeonnement est fréquent, le plus souvent il est tel que nous venons de le déerire ; cependant, dans certains cas, l'épaississement n'existe pas et la capsule se creuse simplement d'un pertuis, sans modification d'épaisseur. Ce phénomène avait déjà été entrevu par Potron chez Torulopsis neoformans oú nous l'avons retrouvé. Cependant, pour cet auteur, il persistait longtemps après la séparation des deux organismes et une cicatrice ombiliquée marquait son emplacement. En fait, il est toujours contemporain d'une période de germination.

Dans les phénomènes de blastèse (Langeron et Guerra 1940), la capsule ne se rompt jamais. La blastospore émet un prolongement qui se coiffe de la capsule, la refoule devant lui, de telle sorte que la formation $d u$ filament initial est toujours intracapsulaire, sans aucune rupture de la capsule. Le comportement capsulaire est le même lorsqu'il y a formation de pseudo-mycélium. Chaque fragment de filament est entouré de la capsule; lorsque le filament bourgeonne à son tour, la capsule subit le même étirement. Les fig. 2 (pl. III) et 5 (pl. VI) illustrent ce fait.

Chez les levures ascosporées, dont le rôle dans l'industrie est important, il existe un mode de reproduction sexuée qui est la formation des ascospores. Nous avons suivi leur formation en examinant des cultures d'abord très jeunes, puis de plus en plus âgées. L'ascospore n'apparait le plus souvent que vers le quinzième jour de culture. Le protoplasme se condense en un point sous forme d'une tache colorée intensément en bleu foncé. Cette tache grandit et prend bientôt la forme caractéristique inhérente à une espèce donnée; elle donne une impression de volume et non plus de surface : l'ascospore est formée.

Pendant cette transformation, le protoplasme, se condensant au maximum dans l'ascospore, perd par ailleurs ses qualités tinctoriales ; il devient uniformément bleu pâle ; il se rétracte. Lorsque l'asque est arrivé à maturité, le protoplasme ne forme plus qu'un reliquat peu important, c'est l'épiplasme, qui se colore par la méthode de Churchman et Emelianoff en bleu très pâle. L'ascospore bleu foncé semble incluse dans cet épiplasme, mais elle en reste toujours séparée par un espace circulaire paraissant vide. L'ectoplasme capsulaire, seule limite visible de la capsule, entoure de toutes parts l'asque ainsi formé.

\section{V. - Caractères biologigues de la capsule}

Bien que l'étude biochimique de la capsule sorte du cadre morphologique de notre étude, nous résumerons rapidement l'état 
actuel de nos connaissances sur la nature chimique de la capsule, ses rapports avec le corps cellulaire, son rôle en immunologie.

A. Nature de la capsule. - Nous avons déjà attiré l'attention, dans un chapitre précédent, sur l'apparence rigide de la capsule des levures; rigidité objectivée par l'aspect en mosaïque des plages cellulaires déshabitées et l'existence de non-concordance de forme entre la capsule et sa cellule.

Il faut rapprocher de cette rigidité la grande résistance de la capsule aux agents chimiques: seuls les bases et les acides forts la dissolvent. Cette « non-réactivité » remarquable a permis de poser l'hypothèse de son rôle protecteur mécanique des constituants cellulaires (R. Dubos, 1946). Potron, admettant déjà ce postulat, et inspiré par les travaux de MaNgin, avait cherché à mettre en évidence dans la capsule des levures les principales substances constitutives de la membrane végétale. Les résultats de ces travaux furent les suivants : la capsule ne contient ni cellulose, ni callose, ni composés pectiques, pourtant si répandus dans le monde végétal, ni lignine, cutine ou subérine. La chitine, si commune dans le revêtement des représentants du règne animal et même chez les champi-

\section{Planche VIII}

FiG. 1. - Torulopsis pulcherrima. - Culture de 24 heures. Très beau réseau de capsules vides, certaines à double contour. Souche $\mathrm{n}^{\circ} 786$.

Fic. 2. - Torulopsis laurentii. - Culture de 8 jours. Plage cellulaire dont les cellules et leur capsule sont noyées par une abondante substance mucilagineuse. Souche $\mathrm{n}^{\circ} 103$.

Fig. 3. - Torulopsis lipofera. - Culture de 5 jours. Souche $\mathrm{n}^{\circ} 105$. Une seule cellule où les grains rouges sont moins visibles que dans la fig. 4.

Fic. 4. - Torulopsis lipofera. - Culture de 5 jours. Souche $\mathrm{n}^{\circ} 105$. Groupe de trois cellules incluses dans leur capsule, celle-ci présentant une magnifique couronne de grains rouges.

Fig. 5. - Torulopsis neoformans. - Culture de 2 jours. Souche $\mathrm{n}^{\circ} 858$. Une cellule isolée. La capsule, bien développée, présente des striations rayonnantes ressemblant aux images décrites par Potron. Le soma est séparé de la capsule par un large espace clair.

Fic. 6. - Nadsonia fulvescens, - Culture de 24 heures. Groupe de cellules dont la capsule, très hypertrophiée, est formée de couches imbriquées les unes dans les autres.

Fic. 7. - Torulopsis neoformans, - Culture de 2 jours. Capsule réticulée, belle aréole claire périsomatique.

Fig. 8. - Torulopsis laurentii. - Culture de 5 jours. Capsule très développée et réticulée.

Fic. 9. - Torulopsis neoformans. - Coupe de lésion blastomycosique. Cas Rubens-Duval et Lœderich. 
ANNALES DE PARASITOLOGIE

Pianche VIII

T. XXIII, Nos 1-2, 1948.

(Mémoire Lenormand)
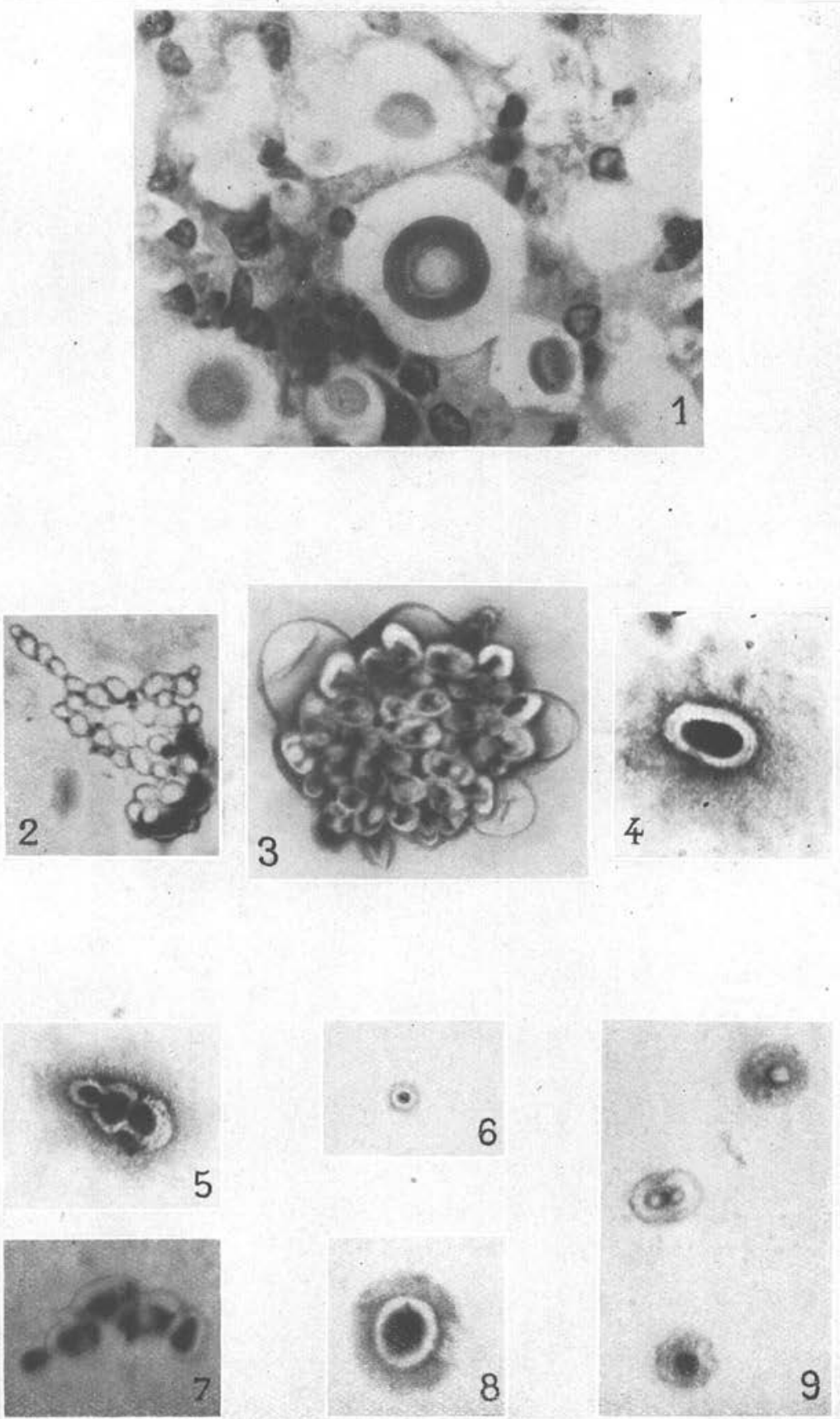

Masson et Cie, Editeurs 

gnons, n'a pas davantage été mise en évidence. Mais il n'alla pas plus loin dans ses recherches. La capsule n'est done formée d'aucune des substances habituellement rencontrées dans les membranes à rôle protecteur.

Des travaux plus récents, et d'ailleurs dépassant largement le cadre des blastomycètes, ont tiré au clair cette question de la nature chimique des capsules. Fait remarquable, il y a identité de nature chimique entre les capsules bactériennes et celles des levures.

Voici résumée l'opinion de R. Dubos (1946) sur ce sujet: La substance capsulaire d'un grand nombre d'espèces bactériennes consiste essentiellement en polysaccharides de poids moléculaire élevé, souvent de nature acide, possédant souvent des groupes acétyl ou aminés, qui se présentent à l'état naturel sous forme de longues chaînes de polymères. La grande asymétrie de leur molécule rend compte de la viscosité de leurs solutions et de leur anisotropie de courant. Ces polysaccharides seraient spécifiques d'une espèce et même d'une souche déterminées. Cette spécificité chimique serait responsable de la spécificité immunologique des différents types sérologiques d'une espèce bactérienne pathogène.

Chez les levures, les recherches modernes ont aussi mis en évidence l'existence de polysaccharides. NEGRoni (1936) traite le matériel capsulaire par une solution de soude à 1 p. 100 à chaud, puis par l'alcool-acétate de sodium à 13 p. 100 qui donne un précipité. Les solutions aqueuses obtenues donnent une réaction de Molisch positive, elles ne réduisent pas la liqueur de Fehling, cette réduction ne s'obtenant qu'après hydrolyse par les acides à chaud ( 15 à 30 minutes d'ébullition sont nécessaires). Par hydrolyse, ces solutions aqueuses de substance capsulaire donnent du glycose décelable par la réaction du glycosazone.

Ce polysaccharide diffuserait dans le milieu de culture où on le précipite par l'alcool-acétate de sodium. Pour l'auteur, il est l'homologue de la « matière gommeuse » sécrétée par la membrane des levures. Cette notion de diffusion du polysaccharide capsulaire dans le milieu de culture a encore été formulée par J. Mager et M. AschNER (1947). Ces auteurs retrouvent dans le milieu où végètent des levures encapsulées une substance polysaccharidique, dont la fraction carbo-hydrate est formée de $85 \%$ de pentoses et $15 \%$ d'hexoses.

Plus rarement, il est vrai, la capsule du bacille du charbon et de quelques autres bacilles aérobies sporulés semble formée d'un polypeptide d'acide d-glutamique (Bonarnick, 1942). Il semble que chez les levures, de tels faits n'aient pu être relevés.

Ann, de Parasitologie, T. XXIII, Nor 1-2, - 1948. 
B. Rôle de la capsule. Ses rapports avec le corps cellulaire. On connait peu de faits concernant l'origine de la capsule et ses rapports avec le corps cellulaire.

Pour les anciens auteurs, le corps sécrète une substance protectrice, sorte de membrane, d'abord en couche mince chez les globules jeunes, pour aboutir dans les vieilles cultures à une capsule épaisse, les stratifications étant le témoignage de cet apport continu de la cellule.

Quelques-uns considèrent la capsule comme étant une couche externe modifiée de la paroi cellulaire, formée par gonflement et gélatinisation de ses constituants.

Les bactériologistes modernes considèrent que la capsule bactérienne correspondrait à une accumulation autour de la cellule d'un produit excrété qui, par suite de sa viscosité et de propriétés spéciales du milieu, n'arrive pas à diffuser rapidement. A l'appui de leur théorie, ils invoquent plusieurs observations, comme le fait que les capsules sont toujours beaucoup plus développées lorsqu'on cultive les microorganismes dans du sérum ou des liquides tissulaires ou bien lorsqu'ils colonisent chez un hôte infecté. Ces milieux présentent en effet une grande viscosité.

Ces différentes notions sont peu acceptables pour les levures et il n'est pas exact de dire que la capsule est plus développée dans les vieilles cultures. Ces notions anciennes ne sont d'ailleurs plus admises de nos jours et nous avons montré dans un chapitre antérieur que le maximum de développement capsulaire avait lieu durant les premiers jours de culture.

Qu'il y ait sécrétion de la cellule, cela n'est pas impossible, bien que les réactions chimiques et tinctoriales de la capsule soient très différentes de celles du corps cellulaire.

Chez les levures, comme chez les bactéries, la capsule semble peu liée à sa cellule. Si on traite le pneumocoque du type III encapsulé par une diastase, celle-ci hydrolyse rapidement la capsule par dépolymérisation (DuBos) et la fait disparaître sans que la vitalité de la cellule en soit affectée. En effet, si on transporte ces cellules décapsulées dans un milieu dépourvu de diastase, la multiplication cellulaire est intense et donne des pneumocoques parfaitement capsulés.

Il en est de même pour les levures dont le corps cellulaire peut se présenter à cheval sur sa capsule et même hors de celle-ci, tout en gardant les apparences tinctoriales d'une cellule jeune et vivante : protoplasme bien coloré, nombreuses granulations, grains de glycogène abondants. 
Cette laxité structurale entre le corps cellulaire et sa capsule nous amène à parler du rôle de cette dernière.

La notion la plus ancienne était de lui octroyer un rôle protecteur. Il n'est plus guère admis actuellement. Mais les conceptions modernes ne sont toutefois que de simples hypothèses.

Au début du siècle, LAFAr (1906) avait déjà établi qu'à la fin de l'activité fermentative des levures, leur gaine muculagineuse est au maximum; les gaines confluent pour former un « réseau gélatineux »; de plus, la gomme retrouvée dans le milieu est un mucilage glycidique optiquement actif vis-à-vis de la lumière polarisée et dont l'hydrolyse ménagée par les acides donne du glycose.

Ce rôle sécrétoire de la capsule ne saurait être mis en doute actuellement. En effet, chez certaines levures, les Torulopsis en particulier, et dans certaines conditions qui ont été précisées par J. Mager et M. Aschner (1947), la capsule produit de l'amidon décelable par sa coloration en bleu par l'iode. Sa production serait conditionnée avant tout par une croissance active de la levure, par la nature de la source d'azote (l'ion ammonium étant indispensable à ce métabolisme) et par un changement de $\mathrm{pH}$ tombant au-dessous de 5. L'apport de vitamines, telle la thiamine à la concentration de 0,2 mgr. par centimètre cube, est un bon adjuvant.

Ces auteurs expérimentèrent avec le même succès sur Torulopsis rotundata et de nombreuses autres espèces du même genre, en particulier $T$. neoformans.

Ce pouvoir sécrétoire de la capsule est complet, puisque l'on retrouve, d'une part, en son sein, à l'exclusion du corps, de nombreux grains d'amidon, et, d'autre part, la même substance dans le milieu de culture, soit sous forme de grains situés au voisinage de la capsule, soit à l'état dissous ; en effet, il suffit de traiter par l'iode le liquide obtenu après centrifugation pour faire apparaître une coloration bleue intense.

Le pouvoir sécrétoire de la capsule est complexe ; à côté de la production d'amidon, on retrouve toujours dans le milieu un autre polysaccharide, dont les propriétés sont tout à fait différentes de celles de la fraction amidon (MAgER et Aschner). Ce corps, retrouvé dans les extraits de capsules, se scinderait en pentoses et en hexoses. Lorsqu'on obtient des variantes non capsulées, il n'y a plus production de pentose.

Enfin, ces deux métabolismes sont indépendants, puisque la suppression de production d'amidon ne gêne en rien la sécrétion de ce polysaccharide.

Il est intéressant de noter que le maximum de développement 
architectural de la capsule coïncide avec le maximum de production d'amidon. Il est alors difficile de concevoir la capsule comme une formation inerte, une simple condensation mucilagineuse, sorte de gel analogue à certaines capsules de pneumocoque mises en évidence par le microscope électronique.

De nombreuses levures, appartenant aux genres les plus variés, sécrètent une substance mucilagineuse pendant leur période de multiplication intense, correspondant d'ailleurs à la période de volume maximum de la capsule. Ce mucilage, assez visqueux pour ne diffuser que lentement dans le milieu, forme une atmosphère plus ou moins étendue autour des levures, qui sont comme agglutinées. C'est

\begin{tabular}{|c|c|c|}
\hline GenRE & EsPÈcE & $\begin{array}{l}\text { DATE D'APPARITION } \\
\text { ET OBSERVATIONS }\end{array}$ \\
\hline 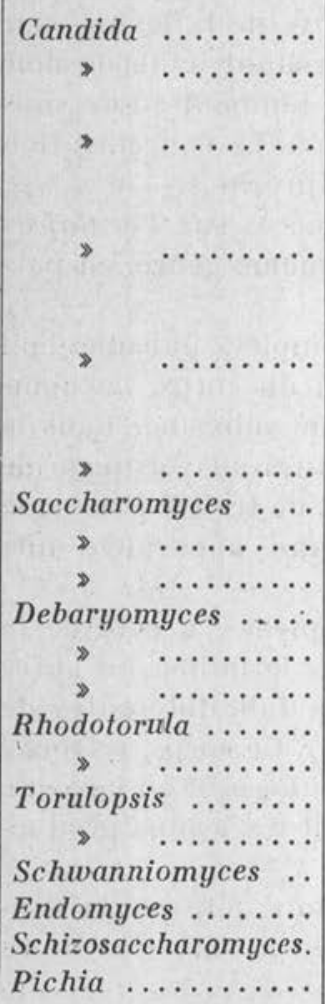 & 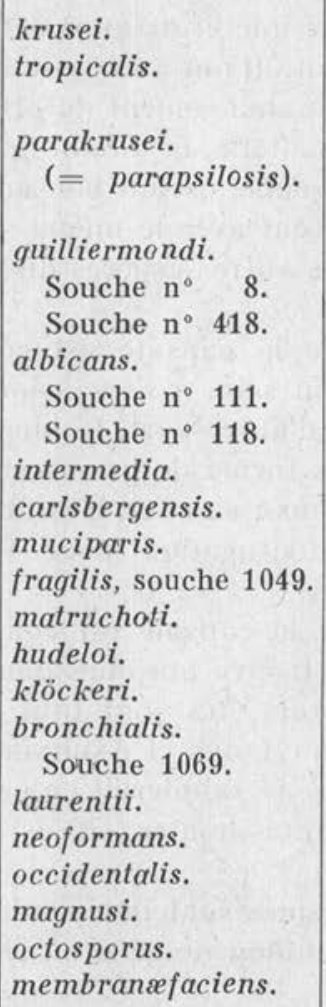 & 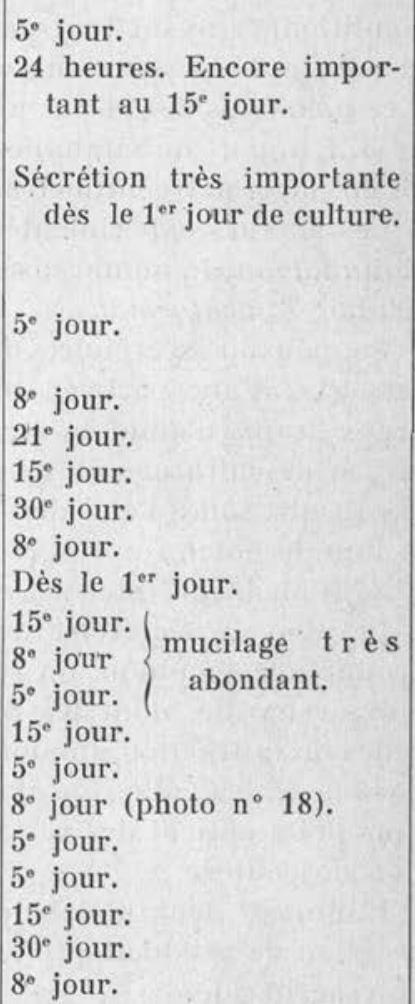 \\
\hline
\end{tabular}


alors que l'aspect macroscopique de la culture est caractéristique : les colonies sont coulantes, difficiles à prélever et encore plus difficiles à émulsionner. Pour certaines souches (Candida tropicalis), le mucilage se présente sous forme de gouttelettes semblant appendues à l'ectoplasme capsulaire. Mais, fait remarquable, quelle que soit l'importance de cette substance, elle ne modifie jamais l'aspect de la capsule qui se détache parfaitement sur le fond rose du mucilage (pl. VIII, fig. 2).

Il est donc difficile d'admettre que la capsule soit une simple condensation mucilagineuse sécrétée par le corps cellulaire.

Cette production est très fréquente, elle a été relevée par de nombreux auteurs et nous l'avons observée chez les espèces suivantes (tableau de la page 100).

C. La capsule en immunologie, - Depuis très longtemps déjà, les microbiologistes avaient été frappés par la taille, particulièrement développée des capsules des bactéries et des levures pathogènes. Cette corrélation entre la virulence et l'encapsulation avait tout naturellement conduit à l'hypothèse que la capsule était une sorte d'armature protectrice des espèces pathogènes et, de plus, qu'elle était le siège même de cette virulence. A tel point que LEgroux pouvait dire : "Une bactérie virulente pour une espèce animale l'est d'autant plus qu'elle présente une capsule et d'autant moins qu'elle en est dépourvue. »

Les recherches sur sa constitution chimique devaient conduire à des découvertes immunologiques. Les polysaccharides et les polypeptides spécifiques des germes pathogènes se comportent comme des haptènes, c'est-à-dire qu'ils réagissent spécifiquement avec les anticorps correspondants, sans pouvoir déterminer leur formation. En effet, si on les inocule à des lapins, ils ne produisent aucun anticorps, alors qu'ils réagissent fortement et spécifiquement avec le sérum de lapins immunisés avec des cellules bactériennes homologues intactes.

D'autre part, si on détruit la capsule, soit par une diastase hydrolysante (DuBos), soit par des lavages répétés, le corps bactérien retient inaltérée sa faculté de déterminer chez l'animal la production d'anticorps qui précipitent spécifiquement avec la substance capsulaire non antigénique.

Les résultats obtenus chez les levures sont en tous points semblables. Le matériel est assez restreint pour cette étude, les levures pathogènes étant une minorité. Aussi les recherches se limitent-elles à Candida albicans et surtout à Torulopsis neoformans, la seule véritablement pathogène. 
C'est à Negroni (1936) que l'on doit les recherches sur Candido albicans. Il extrait d'une part le polysaccharide du milieu de culture par précipitation par l'alcool-acétate de sodium et d'autre part celui de la capsule elle-même, en lavant les cellules dans une solution de soude à 1 p. 100 , puis en précipitant par l'alcool-acétate. Dans les deux cas, les polysaccharides obtenus floculent en présence du sérum d'animaux préparés avec des souches de Candida albicans.

Il recherche, en outre, les réactions d'agglutination en présence d'un sérum spécifique. Pour cela, il divise en cinq lots une culture sur gélose glycosée de Candida albicans :

Le $1^{\text {er }}$ tube contient une suspension des levures dans la solution physiologique.

Le $2^{\circ}$ tube contient la suspension précédente, mais chauffée pendant une heure à 60 degrés.

Dans le $3^{\circ}$ tube, il recueille une suspension de levure lavée six fois par centrifugation dans la solution physiologique.

Le $4^{\bullet}$ tube contient une suspension dans la solution physiologique de levures lavées par centrifugation, quatre fois dans une solution de soude à 1 p. 100 , puis deux fois dans la solution physiologique.

Enfin, le dernier tube est une émulsion de levures maintenue à l'ébullition pendant dix minutes dans une solution de soude à 1 p. 100, puis lavée deux fois dans l'eau physiologique.

Il porte dans chaque tube à hémolyse $0,5 \mathrm{~cm}^{3}$ de la suspension cellulaire et $0,5 \mathrm{~cm}^{3}$ de la dilution du sérum spécifique. Il réserve deux tubes témoins. Il porte au bain-marie à 50 degrés pendant une heure.

Les résultats sont les suivants : l'agglutination se produit dans tous les tubes jusqu'à la dilution $1 / 200$, au delà elle est inconstante. Elle est nulle dans le tube témoin sans sérum et dans le tube contenant du sérum normal.

Enfin, le polysaccharide issu de la capsule ou du milieu de culture donne une réaction de fixation du complément vis-à-vis de sérums de sujets atteints d'affections á Candida albicans ou de sérum animal traité par cette même levure.

Les médecins connaissent la haute virulence de Torulopsis neoformans et le grand développement que prend sa capsule sur l'hôte infecté.

Les animaux de laboratoire les plus sensibles sont le cobaye et la souris. La virulence varie selon les souches. Pour une souche virulente, l'inoculation par voies intrapéritonéale, intraveineuse- et intracérébrale, soit du liquide céphalo-rachidien, soit d'une culture première, amène la mort de la souris dans un délai de 6 à 21 jours. 
A l'autopsie, les poumons et le foie sont très atteints. Chez le cobaye, la résistance est plus grande, une inoculation intrapéritonéale de culture provoque la mort dans un délai de un mois et demi à deux mois. Chez cet animal, la localisation du parasite est cérébrale, et le développement capsulaire est deux et trois fois celui de la cellule.

Cependant, il semble peu probable que les phénomènes de virulence soient liés à la capsule. Nous avions à notre disposition plusieurs souches de Torulopsis neoformans, la plupart anciennes, ayant subi de nombreux repiquages et perdu tout pouvoir pathogène. Grâce à l'obligeance du Prof. Mollaret, nous avons pu examiner une culture première d'une souche virulente, la capsule n'y était pas plus développée que sur les vieilles souches avirulentes de la mycothèque de l'Institut de parasitologie de la Faculté de médécine de Paris.

Accepter l'hypothèse du rôle de la capsule dans la virulence des Torulopsis conduisait tout naturellement à rechercher si elle n'était pas aussi capable de produire des anticorps protecteurs. Les essais d'immunisation de lapins ou de cobayes furent infructueux, que l'on fasse appel à des cultures tuées par la chaleur ou à des cultures vivantes très diluées, et quelle que soit la voie d'inoculation. Il ne fut jamais possible de créer ni anticorps, ni agglutinines, ni précipitines.

Ce défaut d'activité immunologique vient corroborer la suggestion de Benнam, selon laquelle le matériel capsulaire est responsable de l'inertie immunologique des levures. Cette hypothèse est d'ailleurs confirmée par les données histopathologiques des lésions à Torulopsis neoformans, où aucune réaction de défense de l'organe infecté ne peut être relevée. Le tissu réticulo-endothélial parait inerte et les cellules sont lysées, sans que cette invasion parasitaire suscite la moindre réaction de phagocytose, de prolifération cellulaire ou de réaction giganto-cellulaire.

\section{Conchusions}

Jusqu'à maintenant, l'existence de la capsule des levures n'avait été démontrée que chez un petit nombre d'entre elles. Les descriptions étaient restées imprécises et les seuls détails mis en évidence étaient la présence de stratifications et l'aspect épineux.

Cette pauvreté de connaissance semble due à une insuffisance des méthodes de coloration. 
En utilisant l'excellent procédé de Churchman et Emelianoff, nous avons pu démontrer la constance de la capsule dans tous les genres et espèces de levures.

Cette technique nous a permis une description plus précise, faisant apparaitre ainsi un certain nombre de nouveaux caractères architecturaux :

- Anneaux linéaires,

- Arcades,

- Couronnes de grains, intracapsulaires.

Ces différents caractères, isolés chez certaines levures, sont réunis chez Torulopsis neoformans, se surajoutant ainsi chez elle à l'aspect déjà décrit en fruit de châtaignier.

Les modifications très particulières subies par la capsule lors des phénomènes de bourgeonnement des levures, jusqu'ici peu approfondies, ont été aussi précisées.

Nous avons complété ces données morphologiques par une mise au point des notions récentes concernant les propriétés chimiques et biologiques de la capsule.

\section{BIBLIOGRAPHIE}

Bernstein (H. T.). - Capsulation of Neisseria gonorrhaz. Prop. Soc. Exp. Biol., XLVI, 1941, 700-703.

Bonin (P.), - Mise en évidence des capsules microbiennes par une nouvelle méthode à l'encre de Chine. C.R. Soc. Biol., XCII, 1925, 406.

Brenot (J.). - Contribution monographique à l'étude des colorants et des méthodes de coloration en Histologie et en Bactériologie. Thèse de Doctorat Vétérinaire, Vigot Frères, 1939, p. 21-28.

de Busscher, Scherer et Thomas. - La méningite à Torula. Revue Neurologique, LXX, 1938, 149-168.

ButT, Bonynge et Joyce. - The demonstration of capsule about hemolytic streptococci with India ink or azoblue. Jl. Inf. Dis., LVIII, 1936, 5.

Casagrandi. - Ueber die Morphologie der Blastomyceten. Ztrlbl. Bakt., III, 1897.

Churchman (J. W.) et Emelianoff (N. V.). - A study of the bacterial capsule by new methods. J. Exp. Med., LVII, 1933, 485-510.

Debrí (R.), Lamy (M.), Nick (J.), Mlle Grumbach et Normand (E.). - Développement d'une méningite à Torula histolytica chez un enfant de 12 ans atteint de lymphogranulomatose maligne. Bull. Acad. Méd. Paris, CXXX, 1946, 443-449. - Annales prediatrici, CLXVIII, 1947, 1-33.

Dickmann (G. H.), Veppo (A. A.) et Negri (Th.). - Torulopsis del systema nervioso central (cerebelo) de forma tumoral. Rev. Neurol., Buenos-Ayres, VII, 1942, 347-360.

Dosch (F.). - Darstellung der Bakterienhüllen mit dem Chemotherapeuticum Prontosil solubile. Ztrlbl. Bakt., 1, CXLIX, 1942, 56-80. 
Dubos (R.). - The bacterial cell, 1946, p. 36. Harvard University monograph in medicine and public health., $\mathrm{n}^{\circ}$ 6. Cambridge (Mass.), xıx-460 p.

FILIPE (A.). - Inconvénients de la méthode de Burri pour la démonstration de la capsule. Arquivos Instituto Bacteriologico Câmara Pestana, IX, fasc. 1, $77-82$.

Genevray et Barlet. - Sur un cas de blastomycose méningée à Saccharomyces tumefaciens observé au Tonkin. Arch. Inst. Pasteur Indochine, avril 1936.

Goldserg (L. H.). - Torula infection of the central nervous system. Jl. Lab. Clin. Med., XXVI, 1940, 299-301.

Gursteın (M.). - Das Ektoplasma der Bakterien.

I Mitteilung. -- Ueber eine allgemeine Methode zur Darstellung der Ektoplasmas der Grampositiven Bakterien. Ztrlbl. Bakt., 1, XCIII, 1924, $393-402,1 \mathrm{pl}$.

II Mitteilung. - Ueber färberische Verschiedenheiten zwischen Grampositiven und Gramnegativen Bakterien. Eine Beitrag zur Theorie der Gramschen Färbung. Ztrlbl. Bakt., 1, XCIV, 1925, 145-151, 1 pl.

III und IV Mitteilung. - Morphologie und Aufbau der Ektoplasmas der Grampositiven Bakterien. Ztrlbl. Bakt., 1, XCV, 1925, 1-20, 1 pl.

V Mitteilung. - Färberischer Nachweis und chemischer Bau der Ektoplasmas der Gramnegativen Bakterien. Ztrlbl. Bakt., 1, C, 1926, 1-19.

Howie (J. W.) et KIRKPATRICK (J.). - Observations on bacterial capsules as demonstrated by a simple method. Jl. Path. Bact., XXXIX, 1934, 165-169.

Kunstler (J.) et BUSQUET. - Observations sur la structure des Bactériacées et des organismes voisins, 1898 , p. 34 , fig. 39.

LAFAr. - Technische Mykologie. - Tome II, Eumyceten Gahrungen, 1906.

Langeron (M.). - - Précis de Mycologie, Paris, Masson et Cie, 1945, 416-420.

- Précis de Microscopie, 6 édition, Paris, Masson et Cie, 1942, 1089-1090.

Langeron (M.) et Guerra (P.). - Valeur et nature des variations et dissociations de colonies chez les champignons levuriformes. Ann. Paras., Paris, XVII, 1939-1940, 456-461.

Langrad-Niglsen (A.). - Change of capsule in the pneumococi. Act. Path. Microb. Scand., XXI, 1944, 362-369.

Legroux (R.). - L'ectoplasme bactérien, la capsule. Ann. Inst. Pasteur, XXXIX, $1925,382-385$.

Legroux (R.) et Magrou (J.). - Etat organisé des colonies bactériennes. Ann. Inst. Pasteur, XXXIV, 1920, 417-431, pl. II à XII.

MAGer (J.). - Studies on the polysaccharides of capsulated yeasts. Biochem. J., XLI, 1947, 603-609.

Mager (J.) et Aschner (M.). - Stareh reaction as aid in identification of causative agent of european blastomycosis. Proc. Soc. Exp. Biol., LXII, 1946, 71-72.

- Biological studies on capsulated yeasts. J. Bact., LIII, 1947, 283-295.

Mallony (F. B.) et Wright (J. H.). - Pathological technique, 8e éd., 1924.

Morison (J. E.). - Capsulation of hemolytic Streptococci in relation to colony formation. J. Path. Bact., LI, 1940, 401-412.

Negroni (P.). - La capsula de la Mycotorula albicans (Ch. Robin, 1853). Revista Inst. Bacteriol., Buenos-Ayres, VI, 1935, 671-676.

- Poder alérgico del antigeno capsular de Mycotorula albicans. Revista Inst. Brcteriol., Buenos-Ayres, VII, 1936, 386-392. 
Negroni (P.). - Propiedades antigénicas in vitro de la substancia capsular de Mycotorula albicans. Revista Inst. Bacteriol., Buenos-Ayres, VII, 1936, 568-589.

- Etude de la capsule de Mycotorula albicans (Ch. Robin 1853). Ann. Paras., XIV, 1936, 511-516.

- La capsule des Levures. Ann. Paras., XIV, 1936, 501-510, pl. XXIII.

Nıño (F.). - Blastomycosis Humana generalizada (estudio clinico, parasitologico, anatomopathologico y experimental). Mision de estudios de patologia regional argentina, Jujuy (Monographia, $\mathrm{n}^{\circ} 3$, 1934).

Potron (M.). - A propos des Blastomycètes dans les tissus (Recherches morphologiques. Application des caractères de la membrane à la diagnose des Blastomycètes dans les tissus). Thèse de Doctorat en Médecine, Nancy, $1903,72-114$.

SokHEy (S. S.). - The capsule of the plague Bacillus. Jl. Path. Bact., LI, 1940, $87-103,3 \mathrm{pl}$.

Staub (A. M.) et Grabar (P.). - Recherches immunologiques sur la Bactéridie charbonneuse. Rôle de la capsule dans l'immunisation anticharbonneuse C.R. Soc. Biol., CXXXVII, 1943, 623.

Vuilemin et Legrain. - Sur un cas de saccharomycose humaine. Arch. Paras., II, 1900.

WILL. - Die Dauerzellen. Ztrlbl. Bakt., 2, 1896.

\section{Institut de parasitologie}

de la Faculté de Médecine de Paris (Directeur : Prof. E. Brumpt)

Section de mycologie médicale (chef de service: $D^{\mathrm{r}} M$. Langeron). 